IZA DP No. 9061

Illegal Immigration and Fiscal Competition

Subhayu Bandyopadhyay

Santiago M. Pinto

May 2015 


\title{
Illegal Immigration and Fiscal Competition
}

\author{
Subhayu Bandyopadhyay \\ Federal Reserve Bank of St. Louis \\ and IZA \\ Santiago M. Pinto \\ Federal Reserve Bank of Richmond
}
Discussion Paper No. 9061
May 2015

\author{
IZA \\ P.O. Box 7240 \\ 53072 Bonn \\ Germany \\ Phone: +49-228-3894-0 \\ Fax: +49-228-3894-180 \\ E-mail: iza@iza.org
}

Any opinions expressed here are those of the author(s) and not those of IZA. Research published in this series may include views on policy, but the institute itself takes no institutional policy positions. The IZA research network is committed to the IZA Guiding Principles of Research Integrity.

The Institute for the Study of Labor (IZA) in Bonn is a local and virtual international research center and a place of communication between science, politics and business. IZA is an independent nonprofit organization supported by Deutsche Post Foundation. The center is associated with the University of Bonn and offers a stimulating research environment through its international network, workshops and conferences, data service, project support, research visits and doctoral program. IZA engages in (i) original and internationally competitive research in all fields of labor economics, (ii) development of policy concepts, and (iii) dissemination of research results and concepts to the interested public.

IZA Discussion Papers often represent preliminary work and are circulated to encourage discussion. Citation of such a paper should account for its provisional character. A revised version may be available directly from the author. 


\section{ABSTRACT}

\section{Illegal Immigration and Fiscal Competition*}

Reflecting recent enforcement policy activism of US states, this paper examines federal-state overlap of illegal immigration policy in a spatial context. Keeping the US-Mexico context in mind, we assume that labor from a source nation enters a host nation through bordering states. Once in the host, illegal immigrants may stay in the state of entry or move to another state. The host nation's federal government and/or the state governments choose border and internal enforcement policies, and also provide local goods. As a benchmark, we define the completely centralized solution as the case where the federal government chooses all the policies, while the state governments are passive. At higher levels of decentralization (i.e., as states take more responsibility in deciding some of the policies), the overlap of federal and state policies is associated with both vertical and horizontal externalities. Among other results, we find that if inter-state mobility is costless, internal enforcement is overprovided, and border enforcement and local goods are under-provided under decentralization, leading to relatively high levels of illegal immigration. While inter-state migration costs moderate such overprovision/under-provision, extreme levels of inter-state immobility may lead to too little illegal immigration, and an overprovision of local goods.

JEL Classification: $\quad \mathrm{F} 2, \mathrm{H} 4, \mathrm{H} 7$

Keywords: illegal immigration, vertical and horizontal externalities, border and internal enforcement, publicly provided local goods

Corresponding author:

Subhayu Bandyopadhyay

Research Division

Federal Reserve Bank of St. Louis

PO Box 442

St. Louis, MO 63166-0442

USA

E-mail: Subhayu.Bandyopadhyay@stls.frb.org

\footnotetext{
* The views expressed are those of the authors and do not necessarily represent official positions of the Federal Reserve Bank of St. Louis, the Federal Reserve Bank of Richmond, or of the Federal Reserve System.
} 


\section{Introduction}

Recent state level initiatives (in Arizona, Alabama and South Carolina, among others) against the employment of illegal immigrants brings an intranational spatial dimension into the discussion of US illegal immigration enforcement policies. Reflecting this reality, the current paper examines illegal immigration in a spatial framework. In particular, we focus on a context where the host nation's federal and regional governments are responsible for implementing internal and border enforcement policies, in addition to the provision of local goods. The central objective of this study is to qualitatively evaluate the overlap and interplay of such federal and state level enforcement measures and how they interact with parameters like interstate migration costs. Illegal immigrants decide the region or border of entry into the host, and after successfully entering the host, they decide whether to stay in the region of entry or move to a different region within the host. Accordingly, border and internal enforcement policies implemented in one region necessarily affects other regions in the host country. Hence, an appropriate analysis of the effectiveness of illegal enforcement policies requires a model that incorporates these spatial features. While empirical studies on this subject are rapidly emerging, ${ }^{1}$ the development of a concise theoretical framework of analysis that can complement these empirics has not kept pace. This paper should serve as one of the first attempts (to our knowledge) to address this gap.

There is a vast and evolving theoretical literature in the area of illegal immigration, where the focus is more on the source and the host nations rather than on regions within a nation. Ethier (1986) is a seminal contribution in this area, which provides an equilibrium migration framework within a Harris-Todaro type framework. The model assumes that the host nation controls illegal immigration using border and internal enforcement with the objective of restricting illegal immigration to a certain socially desirable target level, or a national income maximizing level. Bond and Chen (1987) builds on this framework to discuss optimal internal enforcement in a context where the host nation is a monopsony in the international labor market. Djajić (1987) considers the problem from the source country perspective, and examines the resource allocation effects of illegal immigration on the host

\footnotetext{
${ }^{1}$ See Amuedo-Dorantes and Bansak (2012), Orrenius and Zavodny (2014), Pena (2014), and Bohn et al. (2014), among others
} 
nation. Bandyopadhyay and Bandyopadhyay (1998) present a model of complementarity versus substitutability of trade and illegal immigration flows between nations. Our paper borrows some elements of this literature, such as its focus on optimal border and internal enforcement policies. However, the novelty of our approach is the consideration of such policies at a more granular level, where, in addition to the national government, the states use a mix of these policy tools. ${ }^{2}$

The conceptual framework within which we model the interaction between states' policies and federal policies is similar to strands of the fiscal federalism and tax competition literature in public economics. From Wilson (1986) and Wildasin (1986), among others, we know that when capital is mobile between regions, tax rates on capital and provision of local public goods may be inefficiently low. Oates and Schwab (1988) further show that a tax on capital to finance local public goods spur distortions in environmental standards. In our model, illegal immigrants are mobile and respond to the differential implementation of regional policies. However, it departs from the traditional models of tax competition in that the policy space is multidimensional and policies are financed through lump-sum taxation.

Along with the horizontal interactions between states, federal and state level immigration policies interact through vertical linkages. In this aspect, our work is related to the literature on decentralized income redistribution, such as Pauly (1973), Brown and Oates (1987), Brueckner (2000) and Pena (2014). These papers claim that decentralized redistributive polices (including welfare programs) would induce an inefficient relocation of lower income households across states. This process could even lead to an underprovision of welfare benefits relative to the centralized solution. A similar result arises in our paper explained by the fact that illegal immigrants are assumed to be attracted by higher levels of locally provided goods, but they do not pay for the cost of providing such goods. Brueckner (2004) and Gordon and Cullen (2012) also examine the tradeoffs between centralization versus decentralization, and describe conditions under which one arrangement

\footnotetext{
${ }^{2}$ This rich literature continues to evolve to account for other relevant factors affecting illegal immigration and current policy concerns. For instance, Gaytan-Fregoso and Lahiri (2000) consider how foreign aid from the host nation to the recipient nation may impact family level decision making in the source nation, where a family member contemplates migration. Woodland and Yoshida (2006) highlight the role of the potential migrant's risk preference in driving illegal immigration, while a recent paper by Djajić and Michael (2014) considers the role of a transit nation in illegal immigration.
} 
is preferred over the other. Even though our focus is quite different, we also attempt to qualitatively examine the policies implemented under various institutional arrangements that grant state and federal governments different degrees of responsibilities. A proper analysis of these issues within a well developed public economics model would shed some light on the implications of decentralizing enforcement activities, especially in a context like the USA where a few states are already undertaking these responsibilities.

There is also a substantial empirical literature that focuses on various aspects of illegal immigration that are related to our work. For instance, contributions such as Spilimbergo and Hanson (1999), and Orrenius and Zavodny (2005), among others, have generally found that illegal immigration flows are quite sensitive to returns to migration. ${ }^{3} \mathrm{Ad}-$ ditionally, the paper by Pena (2014) cited above empirically investigates whether states offering more generous welfare benefits experience greater immigration of undocumented immigrants. ${ }^{4}$ Our analytical framework, driven in part by the findings of this literature, highlights the role of both enforcement and public good provision in affecting illegal immigration flows.

The relatively recent policy activism regarding illegal immigration at the state level in the USA has also spurred several empirical studies to unravel the effects of the state level policies on labor market outcomes. These studies have mainly looked at the effects of state level implementation of specific programs that would be categorized as "internal" enforcement policies. ${ }^{5}$ The E-verify program is an example of such efforts. The U.S. Citizenship and Immigration Services agency describes the program as ${ }^{6}$ "...an Internet-based system that compares information from an employee's Form I-9, Employment Eligibility Verification, to U.S. Department of Homeland Security and Social Security Administration records to confirm employment eligibility." Participation in this program is voluntary, so states can decide whether they will implement this program within their state borders. ${ }^{7}$

\footnotetext{
${ }^{3}$ Hanson (2006) provides a thorough review of the earlier empirical illegal immigration literature.

${ }^{4}$ Using data from the National Agricultural Workers Survey, they find no evidence of such welfare migration for undocumented workers.

${ }^{5}$ The definition of internal enforcement used in the paper is relatively simple compared to the set of programs and policies observed in reality, but it follows the literature on illegal immigration. In most countries, the mechanisms are somewhat more complicated.

${ }^{6}$ See http://www.uscis.gov/e-verify/what-e-verify.

${ }^{7}$ The participation is voluntary except for certain categories of employers such as federal government contractors.
} 
Amuedo-Dorantes and Bansak (2012) analyze the impact of state level use of E-verify mandates and find that such mandates may be especially costly to the extent that they induce a reallocation of unauthorized workers from industries that are affected most by these regulations to others which may enjoy some exclusions (such as agriculture and food services). ${ }^{8}$ Bohn et al. (2014) investigate the effects of Arizona's 2007 Legal Arizona Workers Act (LAWA) which mandates use of E-verify by all Arizona employers for all employees hired after January 1, 2008. A major finding is that they observe a significant reduction in the proportion of the Hispanic noncitizen population of Arizona, but do not find similar declines for Hispanic naturalized citizens. ${ }^{9}$ Amuedo-Dorantes et al. (2013) use survey data based on interviews of voluntary returnees or deportees to Mexico, and find that measures such as E-verify curb internal mobility of unauthorized immigrants and also curb deportees' intentions to return to the US. Orrenius and Zavodny (2014) investigate the effects of such implementation on the labor market outcomes of Mexican immigrants who are likely to be unauthorized. ${ }^{10}$

The present paper develops a stylized model that captures some of the main features summarized earlier. It is built on the following assumptions. Migration of workers can take place between a source and a host country. The host country consists of two regions ${ }^{11}$ that share their borders with the source country. ${ }^{12}$ There are, however, legal restrictions to the movement of labor across countries. The host country enforces illegal immigration laws by devoting resources to catch illegal immigrants at the border (preventing them from entering the country), and by choosing different levels of internal enforcement to determine whether firms employ illegal immigrant workers. Internal and external enforcement may in principle differ across regions (i.e., enforcement levels can be regionally targeted). Moreover, residents in each region have access to locally provided goods. Illegal workers first

\footnotetext{
${ }^{8}$ In this context they encourage a move towards a more comprehensive immigration reform implemented at the federal level.

${ }^{9}$ The authors suggest that this decrease may be due to at least two reasons: those planning to migrate illegally from Mexico to Arizona may choose an alternate location; and existing undocumented workers in Arizona may move elsewhere when they are impacted by LAWA.

${ }^{10}$ Among other findings, they observe that state use of E-verify tends to reduce the average hourly earnings of Mexican immigrants who are likely to be unauthorized, while raising the earnings of naturalized Mexican immigrants and US born Hispanic men.

${ }^{11}$ Throughout the paper we will use the general term "region", but the analysis applies to the relevant jurisdiction level, including states.

${ }^{12}$ An extension of the paper considers a different geographical configuration of the host country, where only one region shares the border with the source country and the other region is "internal".
} 
decide whether to move to the host country, and next, they decide where (in which region of the host) to work, considering that moving across regions entails a cost. The paper compares the provision of enforcement, both at the border and internal, and the level of regional goods chosen under alternative allocations of responsibilities between central and regional governments and under alternative assumptions about mobility costs. ${ }^{13}$ In general, as the provision of enforcement is more decentralized, enforcement levels will tend to depart from the centralized solution due to the presence of several opposing externalities. To the extent that targeted regional border enforcement reduces the overall pool of illegal immigrants, it would generate a positive externality on the other region. Higher levels of targeted regional internal enforcement, on the other hand, would generate a negative externality by diverting illegal immigrants from one region to the other. Additionally, the decentralized provision of the regional good would also contribute to attract or deter illegal immigrants affecting other regions accordingly. Unambiguous conclusions can be derived under certain specific assumptions. ${ }^{14}$ For instance, with costless mobility of illegal immigrants and a fixed amount of potential illegal immigrants, border enforcement and local goods tend to be underprovided in the decentralized case, while internal enforcement tends to be overprovided. Indeed, optimal internal enforcement is zero under centralization, but in spite of this fact, the equilibrium level of illegal immigration is lower under centralization compared to the decentralized case.

The paper is organized as follows. Section 2 introduces the model. In section 3, we characterize the behavior of illegal immigrants conditional on the levels of enforcement and regional good. Section 4 studies the determination of the relevant policy variables under four different institutional arrangements: (i) all policies are decided centrally by the federal government; (ii) all decisions are completely decentralized; (iii) regional governments choose the level of internal enforcement and the level of the regional good, while the federal government decides the level of border enforcement; and (iv) the federal government chooses both internal and border enforcement and the regional government only chooses the level of the regional good. We compare the results obtained in each case in section 5. Sections

\footnotetext{
${ }^{13}$ The paper also considers mixed cases in which each level of government is responsible for implementing specific policies.

${ }^{14}$ We obtain further conclusions by deriving a numerical example.
} 
6 and 7 extends the analysis in two ways: section 6 examines the implications of assuming an endogenous supply of potential illegal immigrants, and section 7 studies how decisions change when illegal immigration is assumed to have redistributive effects within the regions. Section 8 concludes.

\section{The Model}

Consider two countries: a source and a host (or destination) of illegal immigration. Both countries employ labor and a fixed specific factor (land) to produce a homogeneous good. ${ }^{15}$ The host country consists of two regions (jurisdictions or states): $A$ and $B$. The regions share their borders with the source country. Legal restrictions prevent a free movement of labor from the source to the host country. The host country controls illegal immigration using two policy instruments. On one hand, the host country can devote resources to prevent illegal immigrants from entering the country at the border (border enforcement). On the other hand, it can allocate resources to enforce illegal immigration laws internally (internal enforcement). The latter basically consists of inspecting domestic firms and determining whether they employ illegal workers. If firms are caught employing illegal immigrants, they are subject to penalties and workers are deported. Figures (1a) and (1b) help describe the model.

Internal and external enforcement may differ across regions. Specifically, the model assumes that the probability of detecting an illegal immigrant at the border is $q^{i}\left(c^{i}\right)$, where $c^{i}$ is expenditure on enforcement at the border between region $i$ of the host country and the source country. It is assumed that $q(0)=0, q^{i \prime}\left(c^{i}\right)>0, q^{i \prime \prime}\left(c^{i}\right)<0$, and $0 \leq q^{i}\left(c^{i}\right) \leq 1$ for all $c^{i} \geq 0$. A firm operating in region $i$ is detected hiring illegal workers with probability $p^{i}\left(e^{i}\right)$, where $e^{i}$ denotes internal enforcement expenditures in region $i$. Additionally, $p^{i}(0)=$ $0, p^{i \prime}\left(e^{i}\right)>0, p^{i \prime \prime}\left(e^{i}\right)<0$, and $0 \leq p^{i}\left(e^{i}\right) \leq 1$ for all $e^{i} \geq 0$. If a firm is caught hiring illegal workers, it has to pay a penalty of $z^{i}$ per illegal worker. ${ }^{16}$

After observing the levels of border and internal enforcement, workers from the

\footnotetext{
${ }^{15}$ The model can be extended to include capital, and capital may be mobile across regions in the host or across countries.

${ }^{16}$ For simplicity, the probabilities $q^{i}(\cdot)$ and $p^{i}(\cdot)$ only depend on border and internal law enforcement expenditures. In a more general setting, $q^{i}(\cdot)$ may also depend on the number of illegal migrants crossing the border, and $p^{i}(\cdot)$ on the number of illegal workers employed by the firms. Additionally, we assume that $\lim _{e^{i} \rightarrow 0} p^{i \prime}\left(e^{i}\right)=P^{i}$ and $\lim _{c^{i} \rightarrow 0} q^{i \prime}\left(c^{i}\right)=Q^{i}$, where $P^{i}$ and $Q^{i}$ are large enough numbers, and $\lim _{e^{i} \rightarrow \infty} p^{i \prime}\left(e^{i}\right)$ and $\lim _{c^{i} \rightarrow \infty} q^{i \prime}\left(c^{i}\right)$ approach 0.
} 
source country decide to enter the host as illegal immigrants through region $A$ or region $B$, or stay in the source country. Once they enter the host, they choose where (in which region of the host) to reside and work. Illegal immigrants face, however, a cost of moving across regions in the host country. Firms operating in each region of the host decide, at the same time, the number of illegal workers to hire. The functions $f^{i}\left(n^{i}\right), i=A, B$, describe the production technology in the host country, where $n^{i}$ the total number of workers, both legal and illegal, in region $i$ of the host country, with $f^{i \prime}(\cdot)>0, f^{i \prime \prime}(\cdot)<0$, and $f^{i \prime \prime \prime}(\cdot) \geq 0$.

\subsection{Legal residents/workers}

There are $\bar{n}^{i}$ immobile legal residents in region $i$, who also own the local fixed factor. ${ }^{17}$ Individuals derive utility from the consumption of private goods, and from a publicly provided regional good $g^{i} .^{18}$ The consumption of private goods is equal to disposable income $y_{L}^{i}$. Legal residents in $i$ are paid a wage as legal workers $w_{L}^{i}\left(n^{i}\right)=f^{i \prime}\left(n^{i}\right)$, receive rents from the ownership of the fixed factor, and pay taxes. Total rents, given by $\pi^{i} \equiv f^{i}\left(n^{i}\right)-f^{i \prime}\left(n^{i}\right) n^{i}$, are equally divided among legal residents, so each legal resident receives $\pi^{i} / \bar{n}^{i}$. Legal residents pay lump-sum taxes to finance expenditures in law enforcement and the cost of providing the regional public goods. Specifically, the utility of a legal resident of region $i$ is $u_{L}^{i}=y_{L}^{i}+\phi\left(g^{i}\right)$, with $\phi^{\prime}>0, \phi^{\prime \prime}<0, \phi(0)=0$.

\subsection{Illegal residents/workers}

$M^{i}$ workers attempt to enter the host country illegally through region $i$. Each worker faces a cost from such action that depends positively on the number of illegal immigrants attempting to cross through border $i$. We denote this cost by $\mu^{i}\left(M^{i}\right)$, with $\mu^{i \prime}\left(M^{i}\right)>0, \mu^{\prime \prime}{ }^{i}\left(M^{i}\right) \geq 0 .{ }^{19}$ A proportion $q^{i} M^{i}$ are caught at the border, which means that only $\hat{M}^{i}=\left(1-q^{i}\right) M^{i}$ enter the host through region $i$. The total number of illegal

\footnotetext{
${ }^{17}$ In section 7 we consider the distributional impact of illegal immigration policies by distinguishing between their effects on domestic workers and owners of the fixed factor.

${ }^{18}$ In this model, $g^{i}$ is assumed to be a publicly provided private good, such as health services, or maybe education. We assume that the cost of providing the good rises with the number of users. Alternatively, we could have assumed that $g^{i}$ is subject to congestion, so as the number of users increase, the quality and the utility derived from the consumption of this good declines.

${ }^{19}$ This cost may be justified as follows. Imagine that illegal immigrants enter through a single entry point in region $i$. As more illegal immigrants attempt entry through $i$, the cost for an individual illegal immigrant would also increase.
} 
workers in the host country is

$$
\hat{M}=\hat{M}^{A}+\hat{M}^{B}=\left(1-q^{A}\right) M^{A}+\left(1-q^{B}\right) M^{B} .
$$

An illegal worker that succeeds in migrating into region $i$ may stay in region $i$ or move and work in region $j$. Moving to the other region entails an explicit moving cost represented by $\tau$. The number of illegal workers in region $i$ is $m^{i}=m^{i i}+m^{j i}$, where $m^{i i}$ is the number of illegal workers that enter the country through region $i$ and stay there, and $m^{j i}$ the number of those that enter through region $j$ and decide to move and work in region $i$.

The residential localization decision is formalized through a random utility model. Consider the decision of an illegal immigrant that enters the host through region $i$. If he stays in $i$, he obtains a utility $\tilde{u}^{i i}=u^{i}+\varepsilon^{i}$. The first term is a deterministic component described by $u^{i}=y^{i}+\phi\left(g^{i}\right)$. We assume illegal workers do not pay taxes and do not receive rents from the fixed factor, so disposable income is simply the wage received as an illegal worker, i.e., $y^{i}=w^{i}$. An illegal immigrant also receives utility from the regionally provided public good $g^{i}$, captured by $\phi\left(g^{i}\right)$. The term $\varepsilon^{i}$ is a random component. Note that $\varepsilon^{i}$ varies by individual, but we suppress the subscripts to simplify notation. ${ }^{20}$ Since moving to $j$ is costly, the utility of that same illegal worker when he moves from $i$ to $j$ is $\tilde{u}^{i j}=u^{j}-\tau+\varepsilon^{j}$, where $u^{j}=y^{j}+\phi\left(g^{j}\right)$. We assume that $\left(\varepsilon^{i}, \varepsilon^{j}\right)$ are independent (across individuals and regions) Gumbel-distributed random variables. ${ }^{21}$

We consider two alternative scenarios concerning the number of potential illegal immigrants. In the first case, the pool of workers in the source country willing to migrate to the host country is assumed fixed in supply, which means that $\bar{M}=M^{A}+M^{B}$. We assume that a worker that is caught at the border and sent back to the source country will earn an exogenously given wage $w^{*}$. In the second case, the pool of potential migrants is endogenously determined. We assume the total number of workers in the source country

\footnotetext{
${ }^{20}$ This variable may also be thought to capture the illegal immigrant's perception about local attitudes towards immigration.

${ }^{21}$ For convenience, we assume the Gumbel distributions have identical location and scale parameters. In particular, the location parameter is equal to 0 and the scale parameter equal to 1 . These assumptions do not affect our subsequent analysis in any substantial way.
} 
is $\bar{n}^{*}$. A worker that participates in the source country's labor market (either because the worker never attempted to migrate or because the worker was stopped at the border and sent back to the source country) is paid the wage at the source country $w^{*}\left(n^{*}\right)=f^{* \prime}\left(n^{*}\right)$. The wage depends on the number of effective workers in the source country $n^{*}=\bar{n}^{*}-\hat{M}$, with $w^{* \prime}\left(n^{*}\right) \leq 0$.

In both cases, the level of the publicly provided good at the source country is fixed and normalized to 0 , so the utility of a worker residing in the source country that decides not to move is simply $u^{*}=w^{*}$ in the first case, and $u^{*}=w^{*}\left(n^{*}\right)$, in the second case.

\section{$2.3 \quad$ Firms}

We assume that the firm operating in region $i$ can distinguish between legal and illegal workers (complete discernment case). ${ }^{22} \mathrm{~A}$ firm in region $i$ is detected hiring illegal workers with probability $p^{i}\left(e^{i}\right)$. If the firm is caught, it pays a penalty of $z^{i}$ per illegal worker. ${ }^{23}$ In equilibrium, since legal and illegal residents are perfect substitutes in production and firms can discriminate between legal and illegal workers,

$$
w_{L}^{i}=f^{i \prime}\left(\bar{n}^{i}+m^{i}\right), \quad w^{i}=w_{L}^{i}-p^{i}\left(e^{i}\right) z^{i}
$$

\subsection{Governments}

Legal residents pay lump-sum taxes to governments (central or regional governments, depending on the specific institutional arrangement). These taxes are used to finance three types of expenses: the cost of internal enforcement $T_{e}^{i}$, the cost of border enforcement $T_{c}^{i}$, and the cost of providing the publicly provided local good $T_{g}^{i}$. Specifically,

$$
T_{e}^{i}=\sigma^{i} e^{i}+\left(v^{i}-z^{i}\right) p^{i} m^{i}, \quad T_{c}^{i}=\theta^{i} c^{i}, \quad T_{g}^{i}=\left(\bar{n}^{i}+m^{i}\right) \delta^{i} g^{i},
$$

and $T^{i}=T_{e}^{i}+T_{c}^{i}+T_{g}^{i}$. The cost of internal enforcement $T_{e}^{i}$ is the sum of direct enforcement $\operatorname{costs} \sigma^{i} e^{i}$, and the cost of deporting immigrants net of the penalties paid by firms that

\footnotetext{
${ }^{22}$ In the no discernment case, domestic firms cannot discriminate between legal and illegal workers. In this model, a domestic firm in region $i$ hires an illegal immigrant with probability $m^{i} /\left(m^{i}+\bar{n}^{i}\right)$.

${ }^{23}$ The firm maximizes $\pi^{i}=f^{i}\left(\bar{n}^{i}+m^{i}\right)-w_{L}^{i} \bar{n}^{i}-w^{i} m^{i}-p^{i} z^{i} m^{i}$ with respect to $\left\{\bar{n}^{i}, m^{i}\right\}$. The FOCs are

$$
m^{i}: f^{i \prime}\left(\bar{n}^{i}+m^{i}\right)-w_{L}^{i}=0, \quad n^{i}: f^{i \prime}\left(\bar{n}^{i}+m^{i}\right)-w^{i}-p^{i} z^{i} .
$$
}

This means that $w^{i}=w_{L}^{i}-p^{i} z^{i}=f^{i \prime}\left(\bar{n}^{i}+m^{i}\right)-p^{i} z^{i}$. 
hire illegal immigrants $\left(v^{i}-z^{i}\right) p^{i} m^{i}$, where $v^{i}$ is the cost of deporting an illegal immigrant, and $z^{i}$ represents the penalty per worker. Throughout the analysis we assume that $v^{i} \geq z^{i}$. The cost of border enforcement $T_{c}^{i}$ is assumed to increase linearly with $c^{i}$, where $\theta^{i}>0$ is the constant marginal cost. Finally, the marginal cost of $g^{i}$ is given by $\delta^{i}>0$. Note, additionally, that $T_{g}^{i}$ increases with number of users of that good, which includes both local residents and illegal immigrants.

\subsection{Timing of events}

The timing of the model is as follows:

1. Host country government(s): determination of law enforcement expenditures

(a) The government(s) in the host country decides (decide) the levels of border $c^{i}$ and internal enforcement $e^{i}$, and the level of the regional publicly provided good $g^{i}$ for $i=A, B$. When more than one government decide the policy variables, they do so simultaneously.

2. Illegal workers: entry and residential choice

(a) Illegal immigrants decide to enter the county through region $A$ or region $B$. An illegal immigrant entering the country through region $i$ is stopped at the border and returned to the source country with probability $q^{i}$.

(b) Illegal immigrants that successfully entered through region $i$ decide to stay and work in $i$ or move and work in region $j$, with $i \neq j=A, B$. A firm in region $i$ is detected hiring illegal immigrants with probability $p^{i}$. The firm is subject to a penalty of $z^{i}$ per illegal worker employed by the firm.

(c) Equilibrium in regional labor markets. In (a) and (b), individuals assume their decisions do not affect the outcome of the regional labor markets nor the decisions of other potential illegal immigrants. At the end, however, regional labor markets should clear.

We find the Sub-game Perfect Nash equilibria of this game. 


\section{Illegal Workers: Entry and Residential Choice}

In this section, we examine the choices made by prospective illegal workers: migrate to the host or stay in the source country; enter the host country through region $A$ or $B$; and, finally, decide whether to stay in the region of entry or move to the other region.

\subsection{Residential choice}

Consider the decision of an illegal immigrant that has already successfully entered the host country through region $i$. A proportion of the $\hat{M}^{i}=M^{i}\left(1-q^{i}\right)$ illegal immigrants stays in $i$, and the rest moves to $j$. The probability an illegal immigrant stays in $i$ is $\lambda^{i i} \equiv \operatorname{Pr}\left(\tilde{u}^{i i}=\max \left\{\tilde{u}^{i i}, \tilde{u}^{i j}\right\}\right)$, and the probability he moves to $j$ is $\lambda^{i j} \equiv \operatorname{Pr}\left(\tilde{u}^{i j}=\right.$ $\left.\max \left\{\tilde{u}^{i i}, \tilde{u}^{i j}\right\}\right)$. Then, $m^{i i}=\lambda^{i i} \hat{M}^{i}$, and $m^{i j}=\lambda^{i j} \hat{M}^{i}$. As result, the total number of illegal immigrants in each region becomes

$$
\begin{aligned}
& m^{A}=m^{A A}+m^{B A}=\lambda^{A A} \hat{M}^{A}+\lambda^{B A} \hat{M}^{B}, \\
& m^{B}=m^{B B}+m^{A B}=\lambda^{B B} \hat{M}^{B}+\lambda^{A B} \hat{M}^{A} .
\end{aligned}
$$

Given that the $\varepsilon$ 's are identically and independently distributed and follow an extreme value distribution, then

$$
\begin{array}{ll}
\lambda^{A A} \equiv \frac{\exp \left(u^{A}\right)}{\exp \left(u^{A}\right)+\exp \left(u^{B}-\tau\right)}, & \lambda^{A B}=1-\lambda^{A A}, \\
\lambda^{B B} \equiv \frac{\exp \left(u^{B}\right)}{\exp \left(u^{A}-\tau\right)+\exp \left(u^{B}\right)}, & \lambda^{B A}=1-\lambda^{B B} .
\end{array}
$$

\section{$3.2 \quad$ Entry decision}

Suppose initially the pool of illegal immigrants attempting to enter the host country is fixed and equal to $\bar{M}$, such that $\bar{M}=M^{A}+M^{B}$, where $M^{i}$ is the number of illegal immigrants that attempt entry through region $i^{24}$ Prior to the residential choice, an illegal immigrant decides whether to enter the host country through region $A$ or region $B$. This decision is made as before taking wages as given. ${ }^{25}$ The expected utility of an illegal immigrant that already entered the host country through region $i$ is denoted $u_{E}^{i}$ and is

\footnotetext{
${ }^{24}$ We relax this assumption in section 6 .

${ }^{25}$ It should be noted that this choice can also be formalized using a RUM.
} 
defined as

$$
\begin{aligned}
& u_{E}^{A} \equiv \mathbb{E}\left[\max \left\{\tilde{u}^{A A}, \tilde{u}^{A B}\right\}\right]=\log \left[\exp \left(u^{A}\right)+\exp \left(u^{B}-\tau\right)\right]+\gamma \\
& u_{E}^{B} \equiv \mathbb{E}\left[\max \left\{\tilde{u}^{B A}, \tilde{u}^{B B}\right\}\right]=\log \left[\exp \left(u^{A}-\tau\right)+\exp \left(u^{B}\right)\right]+\gamma
\end{aligned}
$$

where $\gamma$ is the Euler-Mascheroni constant. Using this notation, we define the (expected) utility of an illegal immigrant deciding to enter through $i$ as

$$
U_{E}^{i} \equiv q^{i}\left(w^{*}-k\right)+\left(1-q^{i}\right) u_{E}^{i}-\mu^{i}\left(M^{i}\right)
$$

where $w^{*}$ is assumed constant. If $U_{E}^{A}=\max \left\{U_{E}^{A}, U_{E}^{B}, w^{*}\right\}$, illegal immigrants will enter through region $A$, and if $U_{E}^{B}=\max \left\{U_{E}^{A}, U_{E}^{B}, w^{*}\right\}$, they will all enter through $B$. Our focus is on equilibria in which illegal immigrants enter through both regions. In other words, in equilibrium we should observe $U_{E}^{A}=U_{E}^{B} \geq w^{*}$, or

$$
q^{A}\left(w^{*}-k\right)+\left(1-q^{A}\right) u_{E}^{A}-\mu^{A}\left(M^{A}\right)=q^{B}\left(w^{*}-k\right)+\left(1-q^{B}\right) u_{E}^{B}-\mu^{B}\left(M^{B}\right) \geq w^{*} .
$$

\subsection{Labor market equilibrium}

The entry and residential decisions are made individually by potential illegal immigrants from the source country assuming they do not have an effect on other potential illegal immigrants' choices and taking the outcome of the regional labor markets as given. At the end, however, labor markets should clear. The labor demand in region $i$, $w_{L}^{i}=f^{i \prime}\left(\ell^{i}\right) \Rightarrow \ell^{i}=\ell^{i}\left(w_{L}^{i}\right)$. In equilibrium, $\ell^{i}\left(w_{L}^{i}\right)=\bar{n}^{i}+m^{i}$. Illegal immigrants in region $i$ are paid $w^{i}=w_{L}^{i}-p^{i}\left(e^{i}\right) z^{i}$.

\subsection{Equilibrium}

When the pool of migrants is fixed and equal to $\bar{M}$, the equilibrium is defined as follows:

Definition 3.1. Equilibrium (Fixed Supply of Immigrants). When the number of migrants from the source country is fixed at $\bar{M}$, the equilibrium values $\left\{w^{A}, w^{B}, M^{A}, M^{B}\right\}$ are 
implicitly determined by:

$$
w_{L}^{i}=f^{i \prime}\left(n^{i}+m^{i}\right), i=A, B, \quad U_{E}^{A}=U_{E}^{B} \geq w^{*}, \text { and } \bar{M}=M^{A}+M^{B},
$$

where $m^{A}$ and $m^{B}$ are defined in (3) and (4), respectively. The equations determine $\left\{w^{i}(x), M^{i}(x)\right\}_{i=A, B}$, where $x=\left(c^{A}, c^{B}, e^{A}, e^{B}, g^{A}, g^{B}, \bar{M}, \tau\right)$. By substituting the solutions $\left\{w^{i}, M^{i}\right\}$ into (3) and (4), we obtain $m^{i}$.

To derive further results, the rest of the analysis assumes that regions are completely identical. We will therefore focus on symmetric equilibria at which $e^{i}=e, c^{i}=c, g^{i}=g$, $i=A, B \cdot{ }^{26}$ Under these conditions, the symmetric equilibrium is given by $\left\{M^{i}, w^{i}, m^{i}\right\}=$ $\{M, w, m\}$, where $M=\bar{M} / 2, w=f^{\prime}(\bar{n}+m), \hat{M}=\bar{M}(1-q)$, and $m=[(1-q(c)] \bar{M} / 2$.

We characterize the previously defined equilibrium by performing a comparative static analysis with respect to $\left\{c^{i}, e^{i}, g^{i}, \tau\right\}$. The results, which are evaluated at a symmetric equilibrium, are summarized in the following proposition. ${ }^{27}$

Proposition 1. The following comparative static results hold at a symmetric equilibrium for $\tau \in[0, \infty)$ :

(i) $\partial M^{i} / \partial e^{i}=-\partial M^{j} / \partial e^{i} \leq 0$ (with equality when $\tau=0$ ); $\partial m^{i} / \partial e^{i}=-\partial m^{j} / \partial e^{i}<0$; $\partial w^{i} / \partial e^{i}=-\partial w^{j} / \partial e^{i}>0$; and $\partial \hat{M} / \partial e^{i}=0 ;$

(ii) $\partial M^{i} / \partial g^{i}=-\partial M^{j} / \partial g^{i} \geq 0$ (with equality when $\tau=0$ ); $\partial m^{i} / \partial g^{i}=-\partial m^{j} / \partial g^{i}>0$, $\partial w^{i} / \partial g^{i}=-\partial w^{j} / \partial g^{i}<0$; and $\partial \hat{M} / \partial g^{i}=0$;

(iii) $\partial M^{i} / \partial c^{i}=-\partial M^{j} / \partial c^{i} \gtrless 0$ (with $<$ when $\tau=0$ ); $\partial m^{i} / \partial c^{i}<0, \partial m^{j} / \partial c^{i} \gtrless$ $0 ; \partial m^{i} / \partial c^{i}+\partial m^{j} / \partial c^{i}=-q^{\prime} M$ (with $\partial m^{i} / \partial c^{i}=\partial m^{j} / \partial c^{i}$ when $\tau=0$ ); $\partial w^{i} / \partial c^{i}>$ $0, \partial w^{j} / \partial c^{i} \gtrless 0$ (with $\partial w^{i} / \partial c^{i}=\partial w^{j} / \partial c^{i}$ when $\tau=0$ ); and $\partial \hat{M} / \partial c^{i}<0$;

(iv) $\partial w_{L}^{i} / \partial \tau=\partial m^{i} / \partial \tau=\partial M^{i} / \partial \tau=0$. If $\bar{M}$ is large enough, ${ }^{28}$ then $\partial^{2} m^{i} / \partial e^{i} \partial \tau \geq 0$ (with equality at $\tau=0$ ); $\partial^{2} m^{i} / \partial c^{i} \partial \tau<0$; and $\partial^{2} m^{i} / \partial g^{i} \partial \tau \leq 0$ (with equality at $\tau=0$ );

(v) $\partial^{2} m^{i} / \partial e^{i} \partial c^{i}>0 ; \partial^{2} m^{i} / \partial g^{i} \partial c^{i}<0 ;$ and $\partial^{2} m^{i} / \partial e^{i} \partial g^{i}=0$.

A few remarks are worth pointing out from these results. First, $(i)$ states that an increase in $e^{i}$ has no effect on the number of illegal immigrants attempting entry through $i$, $M^{i}$, when $\tau=0$, and simply diverts the entry of illegal immigrants from region $i$ to region

\footnotetext{
${ }^{26}$ To denote identical variables we suppress indexes identifying the regions.

${ }^{27}$ The derivations are shown in Appendix A, which is separately attached.

${ }^{28}$ The Appendix (attached separately) shows that the results hold when $\bar{M} \mu^{\prime}(\bar{M} / 2)>(1-q)$. In particular, the condition is satisfied when $\bar{M}$ is sufficiently large, or when $c$ is sufficiently large. Throughout the analysis, we assume the previous condition is satisfied.
} 
$j$ when $\tau>0$ (i.e., $M^{i}$ decreases and $M^{j}$ increases in exactly the same amount as $e^{i}$ rises). At the same time, a higher level of $e^{i}$ reduces the number of illegal immigrants working in $i, m^{i}$. Wages in each region adjust accordingly in response to $m^{i}$. Specifically, consider the effect of increasing $e^{i}$. Suppose, initially, that $\tau=0$. Then, a higher level of $e^{i}$ does not affect the entry decisions. However, since the firm discerns between legal and illegal residents, an increase in the (expected) cost of hiring an illegal immigrant translates into a lower wage for illegal immigrants. Thus, the immediate effect of a higher level of $e^{i}$ is to reduce $w^{i} .^{29}$ As illegal immigrants now find it less attractive to work in $i$ and start moving to $j, w_{L}^{i}$ will tend to rise. Now suppose that $\tau>0$. In this case, it is less desirable to enter through $i$ than through $j$ because illegal immigrants anticipate they will later move to $j$, which is costly. Hence, $M^{i}$ declines when $e^{i}$ increases and $\tau>0$. A smaller (relative) supply of illegal immigrants in $i$ makes $w_{L}^{i}$ higher. Note, however, that compared to perfect mobility case, the changes in $w_{L}^{i}$ and $m^{i}$ are smaller because both less illegal immigrants enter through $i$ and some of those that enter through $i$ end up moving to the other region. The corresponding effects on region $j$ are exactly the opposite. Concerning the effect of $g^{i}$ on $\left\{w_{L}^{i}, M^{i}, m^{i}\right\}, i=A, B$, stated in $(i i)$, note that lowering $g^{i}$ has the same effect on these variables as increasing $e^{i}$, so a similar reasoning can be used in this case. ${ }^{30}$ Given that we assume for the moment that the pool of potential migrants is fixed at $\bar{M}$, neither $e^{i}$ nor $g^{i}$ affect the total number of effective illegal immigrants $\hat{M}$ in the host. ${ }^{31}$

Second, as stated in $(i i i)$, a change in $c^{i}$, in addition to diverting illegal immigrants from region $i$ to $j$, also reduces the overall pool of (effective) illegal immigrants, $\hat{M}$. Only the latter effect is present at a symmetric equilibrium when $\tau=0$, so wages in both regions unambiguously increase with higher levels of $c^{i}$. When $\tau>0$, an increase in $c^{i}$ reduces the overall number of (effective) illegal immigrants and the supply of illegal immigrants in region $i$, rising wages in the region. The impact on region $j$ is, however, ambiguous. Even though the number of illegal immigrants is smaller, some of those previously entering through $i$ would now enter through $j$, so the supply would tend to rise in $j$ due to this

\footnotetext{
${ }^{29}$ Recall that $w^{i}=w_{L}^{i}-p^{i} z^{i}$.

${ }^{30}$ In other words, the effects $e^{i}$ and $g^{i}$ are qualitatively similar.

${ }^{31}$ If the pool of potential migrants is endogenous, then both $e^{i}$ and $g^{i}$ also affect $\hat{M}$. In fact, changing $e^{i}$ and $g^{i}$ in this case imposes an additional externality on the other region, which has the opposite sign as the one generated by the diversionary effect examined here. We revisit this issue in section 6 .
} 
effect. To the extent that the latter effect dominates the former, $w^{j}$ could even end up declining as $c^{i}$ rises.

Third, point $(i v)$ of the proposition states that at a symmetric equilibrium, the values of $\left\{w_{L}^{i}, M^{i}, m^{i}\right\}, i=A, B$, are independent of $\tau$, but as explained in the previous two paragraphs, the effect of a change in $\left\{c^{i}, e^{i}, g^{i}\right\}$ on $\left\{w_{L}^{i}, M^{i}, m^{i}\right\}, i=A, B$, does depend on $\tau$. Specifically, point $(i v)$ compares the effectiveness of the policies in reducing illegal immigration as mobility costs rise. In first place, note that $\partial m^{i} / \partial c^{i}$ becomes in absolute value larger, and $\partial m^{i} / \partial e^{i}$ becomes in absolute value smaller as $\tau$ increases. In other words, when mobility costs increase, border enforcement becomes more effective than internal enforcement at reducing $m^{i}$. In second place, $(i v)$ states that the impact of $g^{i}$ on $m^{i}$ gets smaller as mobility costs get larger. This means that the same increase in the level of public goods in region $i$ attracts less illegal immigrants to $i$ when $\tau$ is large than when $\tau$ is small. ${ }^{32}$

Fourth, from (iii) we know that $\partial m^{j} / \partial c^{i}=-\partial m^{i} / \partial c^{i}-q^{\prime} M$, and from $(i v)$ we know that $\left|\partial m^{i} / \partial c^{i}\right|$ gets larger as $\tau$ increases. Thus, combining (iii) and (iv), we may infer that $\partial m^{j} / \partial c^{i}$ could become positive for sufficiently large values of $\tau$. Note that $\partial m^{j} / \partial c^{i}$ captures the magnitude of the external on region $j$ generated by raising $c^{i}$. This conclusion is relevant because the sign of the external effect determines to a large extent whether there is under- or overprovision of $c^{i}$ in the decentralized case compared to the centralized solution. Figure (2c) illustrates with a numerical example, the implications on $\partial m^{B} / \partial c^{A}$ of raising $\tau$. It shows that when $\tau$ increases from zero to infinity, $\partial m^{B} / \partial c^{A}$ changes sign from negative to positive.

Finally, $(v)$ compares the effectiveness of each policy in terms of reducing illegal immigration when other policies change. For instance, a higher level of $c^{i}\left(e^{i}\right)$ reduces the impact of $e^{i}\left(c^{i}\right)$ on $m^{i}$. In other words, increasing one type of enforcement reduces the

\footnotetext{
${ }^{32} \mathrm{~A}$ similar result appears in the traditional tax competition literature. In these models, when mobility costs tend to infinity, regional governments can perfectly tailor the level of local goods to satisfy the preferences of immobile local residents, without attracting residents from other regions. In other words, under complete immobility, changing the level of local goods in one region does not affect other regions, so the centralized and decentralized solutions coincide. Mobility in our framework, however, involves not only moving across regions within the host nation, but also across international borders. As a result, illegal immigrants are able to respond to differential levels of $g^{i}$ by entering the host country through different regions. Proposition 1 states that $\partial m^{i} / \partial g^{i}=-\partial m^{j} / \partial g^{i}>0$ holds even when $\tau \rightarrow \infty$, while in the traditional tax competition model this derivative would be zero.
} 
effectiveness of the other type of enforcement. Similarly, $\partial m^{i} / \partial g^{i}$ decreases as $c^{i}$ increases. This means that higher levels of $g^{i}$ will not attract that many illegal immigrants to region $i$ when $c^{i}$ gets larger. However, changes in $e^{i}$ does not affect $\partial m^{i} / \partial g^{i}$.

\section{Choosing Internal and Border Enforcement}

We now examine the problem faced by the host country governments, regional and federal, in choosing the level of border and internal enforcement levels under different institutional arrangements. We consider four alternative scenarios and compare the outcomes reached in each case. In the first scenario, the central government chooses all policy variables: internal enforcement, border enforcement, and the levels of locally provided goods (fully centralized case). In the second scenario, the regional governments choose all the policy variables in a decentralized way (fully decentralized case). The last two scenarios consider mixed cases. In the first mixed case, the central government chooses the level of border enforcement and regional governments choose internal enforcement and the level of local goods (mixed case $X_{1}$ ). In the second mixed case, the central government chooses border and internal enforcement, and regional governments only choose the level of local goods (mixed case $\left.X_{2}\right) \cdot{ }^{33}$ In what follows, we assume that governments only care about the well-being of legal residents with the following caveat: while the regional governments are only concerned about the well-being of legal residents in their respective regions, the central government takes into account the well-being of all legal residents, regardless of where they reside.

\subsection{Fully Centralized Solution (C)}

In this case, the central government chooses the levels of $\left\{e^{i}, g^{i}, c^{i}: i=A, B\right\}$, that maximize the total utility of all domestic legal residents $U_{L}=U_{L}^{A}+U_{L}^{B}=\bar{n}^{A} u_{L}^{A}+\bar{n}^{B} u_{L}^{B}$, where $u_{L}^{i}=w_{L}^{i}+\pi^{i} / \bar{n}^{i}-\left(T^{A}+T^{B}\right) /\left(\bar{n}^{A}+\bar{n}^{B}\right)+\phi\left(g^{i}\right)$. As explained earlier, the income of a legal resident in region $i$ is given by the legal wage $w_{L}^{i}$, and the share $1 / \bar{n}^{i}$ of the returns to the fixed factor $\pi^{i}$. A legal resident pays (lump-sum) taxes only to the central government. Taxes cover total expenses in both regions. Substituting into the objective

\footnotetext{
${ }^{33}$ The institutional arrangements examined in the paper attempt to characterize different possible allocation of responsibilities across governments in enforcing illegal immigration.
} 
function, the central government's problem can be rewritten as

$$
\begin{aligned}
\max _{\left\{e^{i}, c^{i}, g^{i}\right\}_{i=A, B}} U_{L}= & f^{A}\left(\bar{n}^{A}+m^{A}\right)-f^{\prime A}\left(\bar{n}^{A}+m^{A}\right) m^{A}+\bar{n}^{A} \phi\left(g^{A}\right)-T^{A} \\
& +f^{B}\left(\bar{n}^{B}+m^{B}\right)-f^{\prime B}\left(\bar{n}^{B}+m^{B}\right) m^{B}+\bar{n}^{B} \phi\left(g^{B}\right)-T^{B}
\end{aligned}
$$

The Kuhn-Tucker conditions are characterized by

$$
\begin{aligned}
\frac{\partial U_{L}}{\partial e^{i}} \equiv & \frac{\partial U_{L}^{i}}{\partial e^{i}}+\frac{\partial U_{L}^{j}}{\partial e^{i}} \\
= & -\left[f^{i \prime \prime} m^{i}+\left(v^{i}-z^{i}\right) p^{i}+\delta^{i} g^{i}\right] \frac{\partial m^{i}}{\partial e^{i}}-\left[\sigma^{i}+\left(v^{i}-z^{i}\right) p^{\prime i} m^{i}\right] \\
& -\left[f^{\prime \prime} j m^{j}+\left(v^{j}-z^{j}\right) p^{j}+\delta^{j} g^{j}\right] \frac{\partial m^{j}}{\partial e^{i}} \leq 0, \\
\frac{\partial U_{L}}{\partial c^{i}} \equiv & \frac{\partial U_{L}^{i}}{\partial c^{i}}+\frac{\partial U_{L}^{j}}{\partial c^{i}} \\
\equiv & -\left[f^{i \prime \prime} m^{i}+\left(v^{i}-z^{i}\right) p^{i}+\delta^{i} g^{i}\right] \frac{\partial m^{i}}{\partial c^{i}} \\
& -\left[f^{j \prime \prime} m^{j}+\left(v^{j}-z^{j}\right) p^{j}+\delta^{j} g^{j}\right] \frac{\partial m^{j}}{\partial c^{i}}-\theta^{i} \leq 0, \\
\frac{\partial U_{L}}{\partial g^{i}} \equiv & \frac{\partial U_{L}^{i}}{\partial e^{i}}+\frac{\partial U_{L}^{j}}{\partial e^{i}} \\
= & -\left[f^{i \prime \prime} m^{i}+\left(v^{i}-z^{i}\right) p^{i}+\delta^{i} g^{i}\right] \frac{\partial m^{i}}{\partial g^{i}}+\left[\bar{n}^{i} \phi^{\prime}\left(g^{i}\right)-\left(\bar{n}^{i}+m^{i}\right) \delta^{i}\right] \\
& -\left[f^{j \prime \prime} m^{j}+\left(v^{j}-z^{j}\right) p^{j}+\delta^{j} g^{j}\right] \frac{\partial m^{j}}{\partial g^{i}} \leq 0,
\end{aligned}
$$

for $i \neq j=1,2$, and the corresponding non-negativity constraints $e^{i} \geq 0, c^{i} \geq 0, g^{i} \geq 0$.

The terms

$$
\left[f^{i \prime \prime} m^{i}+\left(v^{i}-z^{i}\right) p^{i}+\delta^{i} g^{i}\right] \text { and }\left[f^{j \prime \prime} m^{j}+\left(v^{j}-z^{j}\right) p^{j}+\delta^{j} g^{j}\right]
$$

play a crucial role in the analysis. These expressions capture the effect on local residents of a change in the number of illegal immigrants in region $i$ and $j$ due to a change in the policy variable $\left\{e^{i}, c^{i}, g^{i}\right\}$. Consider a policy change in $i$ that reduces the presence of illegal immigrants in region $i$. As a result, local residents are affected in three ways. First, since $m^{i}$ declines, deporting costs decrease, so legal residents pay lower taxes. The decline in costs, and consequently taxes, is equal to $\left(v^{i}-z^{i}\right) p\left(e^{i}\right) \geq 0$. Second, since a smaller number of illegal residents benefit from the locally provided good, the cost of financing its 
provision falls in $\delta^{i} g^{i}$. And third, total income received by local residents decline in the amount $\left(-f^{i \prime \prime} m^{i}\right) .{ }^{34}$ Similar effects take place in region $j$ when changes in the policy variables $e^{i}, c^{i}$, and $g^{i}$ affect $m^{j}$. The other terms in the FOCs capture the direct effects of the policy variables on legal residents in $i .{ }^{35}$ The system of equations (11) - (13) determine the centralized solution denoted by $\left\{e_{C}^{i}, c_{C}^{i}, g_{C}^{i}: i=A, B\right\}$.

\subsection{Fully Decentralized Solution (D)}

Suppose that $\left\{e^{i}, c^{i}, g^{i}\right\}, i=A, B$, are determined in a decentralized way. Each region maximizes the total utility of local legal residents $U_{L}^{i}=\bar{n}^{i} u_{L}^{i}$ and faces the cost of providing interior and border enforcement at its own border, and the cost of publicly providing the regional good. The problem for the regional government in $i$ is

$$
\max _{\left\{e^{i}, c^{i}, g^{i}\right\}} U_{L}^{i}=f^{i}\left(\bar{n}^{i}+m^{i}\right)-f^{i \prime}\left(\bar{n}^{i}+m^{i}\right) m^{i}+\bar{n}^{i} \phi\left(g^{i}\right)-T^{i}
$$

taking $\left\{e^{j}, g^{j}, c^{j}\right\}$ as given. The Kuhn-Tucker conditions are given by

$$
\begin{aligned}
& \frac{\partial U_{L}^{i}}{\partial e^{i}} \equiv-\left[f^{i \prime \prime} m^{i}+\left(v^{i}-z^{i}\right) p^{i}+\delta^{i} g^{i}\right] \frac{\partial m^{i}}{\partial e^{i}}-\left[\sigma^{i}+\left(v^{i}-z^{i}\right) p^{\prime i} m^{i}\right] \leq 0, \\
& \frac{\partial U_{L}^{i}}{\partial c^{i}} \equiv-\left[f^{i \prime \prime} m^{i}+\left(v^{i}-z^{i}\right) p^{i}+\delta^{i} g^{i}\right] \frac{\partial m^{i}}{\partial c^{i}}-\theta^{i} \leq 0 \\
& \frac{\partial U_{L}^{i}}{\partial g^{i}} \equiv-\left[f^{i \prime \prime} m^{i}+\left(v^{i}-z^{i}\right) p^{i}+\delta^{i} g^{i}\right] \frac{\partial m^{i}}{\partial g^{i}}+\left[\bar{n}^{i} \phi^{\prime}-\left(\bar{n}^{i}+m^{i}\right) \delta^{i}\right] \leq 0,
\end{aligned}
$$

in addition to the non-negativity constraints $e^{i} \geq 0, c^{i} \geq 0, g^{i} \geq 0, i=A, B$. The solution is denoted $\left\{e_{D}^{i}, c_{D}^{i}, g_{D}^{i}: i=A, B\right\}$.

\subsection{Mixed Case $1\left(X_{1}\right)$ : Decentralized Provision of Local Goods and Internal Enforcement and Centralized Border Enforcement}

Consider a mixed case in which $\left\{c^{i}: i=A, B\right\}$ is determined by the central government authority, and $\left\{e^{i}, g^{i}: i=1,2\right\}$ by the respective regional governments in a decentralized way. The policy variables are all chosen simultaneously. The utility of a legal

\footnotetext{
${ }^{34}$ Recall that total income in region $i$ is $f^{i}-f^{i \prime}\left(\bar{n}^{i}+m^{i}\right) m^{i}$. As $m^{i}$ decreases, total income in $i$ decreases in $\left(-f^{i \prime \prime} m^{i}\right)>0$. We will consider an alternative setup in section 7 that weights differently income received by labor and income received by the owners of the fixed factor.

${ }^{35}$ Similar expressions will be observed in all other cases.
} 
resident of region $i$ is

$$
u_{L}^{i}=w_{L}^{i}+\pi^{i} / \bar{n}^{i}+\phi\left(g^{i}\right)-T_{e}^{i} / \bar{n}^{i}-T_{c} /\left(\bar{n}^{A}+\bar{n}^{B}\right)-T_{g}^{i} / \bar{n}^{i}
$$

In this case, the total cost of border enforcement, $T_{c}=T_{c}^{A}+T_{c}^{B}=\theta^{A} c^{A}+\theta^{B} c^{B}$, is equally shared among the entire legal resident population $\bar{n}^{A}+\bar{n}^{B}$. As a result, a legal resident of the host country pays $T_{c} /\left(\bar{n}^{A}+\bar{n}^{B}\right)$ to the central government. The government in region $i$ maximizes $U_{L}^{i}=\bar{n}^{i} u_{L}^{i}$ with respect to $\left\{e^{i}, g^{i}\right\}$, or

$$
\begin{aligned}
\max _{\left\{e^{i}, g^{i}\right\}} U_{L}^{i}= & f^{i}\left(\bar{n}^{i}+m^{i}\right)-f^{i \prime}\left(\bar{n}^{i}+m^{i}\right) m^{i}+\bar{n}^{i} \phi\left(g^{i}\right) \\
& -T_{e}^{i}-\left[\bar{n}^{i} /\left(\bar{n}^{A}+\bar{n}^{B}\right)\right] T_{c}-T_{g}^{i}
\end{aligned}
$$

taking $\left\{e^{j}, g^{j}, c^{A}, c^{B}\right\}$ as given. The Kuhn-Tucker conditions are exactly the same as those described in (16) and (18). Now, consider the central government's problem. As before, the central government's objective function is $U=U_{L}^{A}+U_{L}^{B}$. When choosing $\left\{c^{A}, c^{B}\right\}$, the central government takes $\left\{e^{A}, e^{B}, g^{A}, g^{B}\right\}$ as given. The expressions resulting in this case are exactly the same as those described by (12). The Nash Equilibrium, denoted $\left\{e_{X_{1}}^{i}, c_{X_{1}}^{i}, g_{X_{1}}^{i}: i=A, B\right\}$, is the solution of the system of equations (12), (16), and (18).

\subsection{Mixed Case $2\left(X_{2}\right)$ : Decentralized Provision of Local Goods and Centralized Internal and Border Enforcement}

Finally, consider a different mixed case in which $\left\{e^{i}, c^{i}: i=A, B\right\}$ are determined by the central government authority, and $\left\{g^{i}: i=1,2\right\}$ by the regional governments. The utility of a legal resident of region $i$ is the same as before except for the financing of the government expenditures. Specifically,

$$
u_{L}^{i}=w_{L}^{i}+\pi^{i} / \bar{n}^{i}+\phi\left(g^{i}\right)-\left(T_{e}+T_{c}\right) /\left(\bar{n}^{A}+\bar{n}^{B}\right)-T_{g}^{i} / \bar{n}^{i}
$$

In this case, total enforcement $T_{e}+T_{c}=\left(T_{c}^{A}+T_{c}^{B}\right)+\left(T_{c}^{A}+T_{c}^{B}\right)$ is equally shared among the entire legal resident population. The government in region $i$ simply maximizes $U_{L}^{i}=\bar{n}^{i} u_{L}^{i}$ 
with respect to $g^{i}$, or

$$
\begin{aligned}
\max _{\left\{g^{i}\right\}} U_{L}^{i}= & f^{i}\left(\bar{n}^{i}+m^{i}\right)-f^{i \prime}\left(\bar{n}^{i}+m^{i}\right) m^{i}+\bar{n}^{i} \phi\left(g^{i}\right) \\
& -\left[\bar{n}^{i} /\left(\bar{n}^{A}+\bar{n}^{B}\right)\right]\left(T_{e}+T_{c}\right)-T_{g}^{i},
\end{aligned}
$$

taking $\left\{g^{j}, e^{A}, e^{B}, c^{A}, c^{B}\right\}$ as given. The Kuhn-Tucker conditions are

$$
\begin{aligned}
\frac{\partial U_{L}^{i}}{\partial g^{i}} \equiv & -\left[f^{i \prime \prime} m^{i}+\frac{\bar{n}^{i}}{\left(\bar{n}^{A}+\bar{n}^{B}\right)}\left(v^{i}-z^{i}\right) p^{i}+\delta^{i} g^{i}\right] \frac{\partial m^{i}}{\partial g^{i}}-\frac{\bar{n}^{i}}{\left(\bar{n}^{A}+\bar{n}^{B}\right)}\left(v^{j}-z^{j}\right) p^{j} \frac{\partial m^{j}}{\partial g^{i}} \\
& +\left[\bar{n}^{i} \phi^{\prime}\left(g^{i}\right)-\left(\bar{n}^{i}+m^{i}\right) \delta^{i}\right] \leq 0,
\end{aligned}
$$

The central government's problem consists of maximizing $U=U_{L}^{A}+U_{L}^{B}$, by choosing $\left\{e^{A}, e^{B}, c^{A}, c^{B}\right\}$, taking $\left\{g^{A}, g^{B}\right\}$ as given. The expressions resulting from the central government's first-order conditions are exactly the same as those described by (11) and (12). The Nash Equilibrium in this case, denoted $\left\{e_{X_{2}}^{i}, c_{X_{2}}^{i}, g_{X_{2}}^{i}: i=A, B\right\}$, is the solution of the system of equations (11), (12), and (21).

\section{Comparing the Solutions: Fixed Supply of Illegal Immi- grants}

In this section, we focus exclusively on the case where the supply of migrants from the source country is fixed in supply at $\bar{M}$. Consider, in first place, the fully centralized and decentralized solutions. In general, evaluating the centralized FOCs at $\left\{e_{D}^{i}, c_{D}^{i}, g_{D}^{i}\right.$ : $i=A, B\}$ gives

$$
\begin{aligned}
& \frac{\partial U_{L}}{\partial e^{i}}=\frac{\partial U_{L}^{j}}{\partial e^{i}} \equiv-\left[f^{j \prime \prime} m^{j}+\left(v^{j}-z^{j}\right) p^{j}+\delta^{j} g^{j}\right] \frac{\partial m^{j}}{\partial e^{i}} \\
& \frac{\partial U_{L}}{\partial c^{i}}=\frac{\partial U_{L}^{j}}{\partial c^{i}} \equiv-\left[f^{j \prime \prime} m^{j}+\left(v^{j}-z^{j}\right) p^{j}+\delta^{j} g^{j}\right] \frac{\partial m^{j}}{\partial c^{i}} \\
& \frac{\partial U_{L}}{\partial g^{i}}=\frac{\partial U_{L}^{j}}{\partial g^{i}} \equiv-\left[f^{j \prime \prime} m^{j}+\left(v^{j}-z^{j}\right) p^{j}+\delta^{j} g^{j}\right] \frac{\partial m^{j}}{\partial g^{i}},
\end{aligned}
$$

since $\partial U_{L}^{i} / \partial e^{i}=\partial U_{L}^{i} / \partial c^{i}=\partial U_{L}^{i} / \partial g^{i}=0$. Expressions $(22)-(24)$ reveal that the centralized and decentralized solutions do not necessarily coincide. Specifically, these expressions describe the external effects imposed by region $i$ on region $j$, not internalized by the authorities in $i$ when they decide the policy variables in a decentralized way. 
As mentioned earlier, our analysis focuses on symmetric equilibria at which $e^{i}=e$, $c^{i}=c, g^{i}=g, i=A, B$. The equilibrium in the second stage is, consequently, given by $\left\{M^{i}, w^{i}, m^{i}\right\}=\{M, w, m\}$, where $M=\bar{M} / 2, w=f^{\prime}(\bar{n}+m), \hat{M}=\bar{M}(1-q)$, and $m^{i}=m=[(1-q(c)] \bar{M} / 2$.

Consider the fully centralized case. At a symmetric solution, $\partial m^{i} / \partial e^{i}=-\partial m^{j} / \partial e^{i}$. As a result, $\partial U_{L} / \partial e^{i}=-\left[\sigma+(v-z) p^{\prime}(e) m\right]<0$, which means that $e_{C}^{A}=e_{C}^{B}=0$. Additionally, by substituting $\partial m^{i} / \partial c^{i}+\partial m^{j} / \partial c^{i}=-q^{\prime}(c) M$ into (12) and by using $\partial m^{i} / \partial g^{i}=-\partial m^{j} / \partial g^{i}$ in (13), we obtain that $c_{C}$ and $g_{C}$ are jointly determined by

$$
\begin{aligned}
& {\left[f^{\prime \prime} m+\delta g\right] q^{\prime}(c) M-\theta=0,} \\
& \phi^{\prime}(g)-\frac{(\bar{n}+m)}{\bar{n}} \delta=0
\end{aligned}
$$

where $m=[1-q(c)](\bar{M} / 2)$ and $M=\bar{M} / 2$. A similar reasoning can be applied to conclude that in mixed case $X_{2}$, the levels of internal enforcement chosen by the central government are zero as well, i.e. $e_{X_{2}}^{A}=e_{X_{2}}^{B}=0$.

However, the latter does not necessarily hold in the completely decentralized case nor in mixed case $X_{1} \cdot{ }^{36}$ Consider the expression $\left(\partial U_{L}^{i} / \partial e^{i}\right)$ in these two cases:

$$
\frac{\partial U_{L}^{i}}{\partial e^{i}} \equiv-\left[f^{\prime \prime} m+(v-z) p(e)+\delta g\right] \frac{\partial m^{i}}{\partial e^{i}}-\left[\sigma+(v-z) p^{\prime}(e) m\right]
$$

An interior solution for internal enforcement would be observed in the decentralized and mixed $X_{2}$ cases whenever $\partial U_{L}^{i} / \partial e^{i}=0$ at $e>0$. Note that the first term in (27) captures the effect of a change in the number of illegal immigrants on the utility of local residents due to an increase in $e$. Since $\left(\partial m^{i} / \partial e^{i}\right)<0$, the first term would be positive if the expression between squared brackets is positive. The latter holds when as a result of a smaller presence of illegal immigrants in the region, deporting costs and the cost of providing the local good decrease more than the decline in total regional income. The second expression in brackets represents the increase in the direct costs of a raising $e$ and is positive. ${ }^{37}$ Under certain

\footnotetext{
${ }^{36}$ Recall that $v^{i} \geq z^{i}$ and $\partial m^{i} / \partial e^{i}<0$ for all $e^{i} \geq 0$. As a result, if $\partial U_{L}^{i} / \partial e^{i}<0$, then $\partial U_{L} / \partial e^{i}<0$ for all $e^{i} \geq 0$, but the converse is not necessarily true. This means that if the solutions in the decentralized and mixed $X_{1}$ cases are such that $e_{D}=e_{X_{1}}=0$, then the solution in the centralized case is $e_{C}=0$ (in fact, the latter always holds). However, the converse is not true.

${ }^{37}$ This expression consists of two parts. The first term is the cost of providing an additional unit of
} 
parameter conditions, there exists a value of $e>0$ at which the two expressions are equal, so that $\partial U_{L}^{i} / \partial e^{i}=0 .^{38}$

For the purpose of our analysis, we assume that the condition $\left[f^{\prime \prime} m+(v-z) p(e)+\right.$ $\delta g]>0$ is satisfied. Similarly, from (17) and given that $\partial m^{i} / \partial c^{i}<0$, it is clear that for $c$ to be strictly positive, this same condition should hold in equilibrium. The following proposition summarizes the previous results.

Proposition 2. At a symmetric equilibrium, the solutions in the centralized and mixed $X_{2}$ cases entail no interior enforcement of illegal immigration, i.e., $e_{C}=e_{X_{2}}=0$. In the decentralized and mixed $X_{1}$ cases internal enforcement maybe zero or positive, i.e, $e_{D} \geq 0$, $e_{X_{1}} \geq 0$.

The proposition states that internal enforcement in the decentralized case is never underprovided relative to the centralized or mixed $X_{1}$ cases. In fact, when condition (27) is met, $e^{i}$ will end up being overprovided.

In comparing the solutions, it is relevant to highlight that the values of $c$ and $g$ in the (symmetric) centralized case, determined by (25) and (26), do not depend on $\tau$. However, the latter does not hold in all cases that involve some kind of decentralized decision.

\subsection{Perfect Mobility Across Regions: $\tau=0$}

Suppose, initially, that once illegal immigrants successfully enter the host country, they can freely move across regions, i.e., $\tau=0$. Evaluating the FOCs of the centralized case for $c^{i}$ and $g^{i}$ at the symmetric decentralized solution $\left\{e_{D}, c_{D}, g_{D}\right\}$ gives $\partial U_{L} / \partial c^{i}>0$ and $\partial U_{L} / \partial g^{i}>0 .{ }^{39}$ This means that starting at this point, the central authority should increase both $c^{i}$ and $g^{i}$. Since in the symmetric case $\partial^{2} U_{L} / \partial c^{i} \partial g^{i}>0,{ }^{40}$ then the curves $\partial U_{L} / \partial c^{i}$ and $\partial U_{L} / \partial g^{i}$ shift to the right as $g^{i}$ and $c^{i}$ increase. As a result, both $c^{i}$ and $g^{i}$ end up being unambiguously higher in the centralized case. ${ }^{41}$ Moreover, as mentioned

$e$, denoted with $\sigma$. The second term is the increase in deporting costs. A higher level of $e$ increases the probability of detecting an illegal immigrant by $p^{\prime}(e)$, so $p^{\prime}(e) m$ additional illegal immigrants would be deported. Since, the net cost of sending an illegal immigrant back to the source country is $(v-z) \geq 0$, then a higher $e$ would increase costs in $(v-z) p^{\prime}(e) m$.

${ }^{38}$ Appendix B (attached separately) discusses some of the conditions for an interior solution of $e$ in the decentralized case.

${ }^{39}$ Refer to expressions (23) and (24). From the comparative static results summarized in Proposition 1 , $\partial m^{j} / \partial c^{i}=\partial m^{j} / \partial c^{i}<0$ at a symmetric equilibrium with $\tau=0$.

${ }^{40}$ This result is shown in Appendix A.3., which is separately attached.

${ }^{41}$ In addition to $\left(\partial^{2} U_{L} / \partial c^{i} \partial c^{i}\right)<0$ and $\left(\partial^{2} U_{L} / \partial g^{i} \partial g^{i}\right)<0$, the SOCs require that the direct effects are stronger than the indirect effects, i.e., $\left(\partial^{2} U_{L} / \partial c^{i} \partial c^{i}\right)\left(\partial^{2} U_{L} / \partial g^{i} \partial g^{i}\right)-\left(\partial^{2} U_{L} / \partial c^{i} \partial g^{i}\right)^{2}>0$. Alternatively, 
earlier, internal enforcement in the decentralized case will never be underprovided: it will be either overprovided or provided at the same level as in the centralized case. Hence, we conclude that $e_{D} \geq e_{C}, c_{C}>c_{D}$, and $g_{C}>g_{D}$. Using a similar reasoning, we can compare the solutions of the centralized and mixed $X_{2}$ cases and conclude that $e_{X_{2}} \geq e_{C}, c_{X_{2}}>c_{D}$, and $g_{X_{2}}>g_{D} \cdot{ }^{42}$

It is straightforward to compare the solutions of mixed cases $X_{1}$ and $X_{2}$ when $v=z$. Substituting the solutions $\left\{e_{X_{1}}, c_{X_{1}}, g_{X_{1}}\right\}$ into the FOCs of mixed case $X_{2}$ gives

$$
\frac{\partial U_{L}}{\partial c^{i}} \equiv-(v-z) p q^{\prime} M, \quad \frac{\partial U_{L}^{i}}{\partial g^{i}} \equiv(v-z) p \frac{\partial m^{i}}{\partial g^{i}}
$$

Hence, if $v=z$, the solutions in both cases are exactly the same, i.e., $c_{X_{1}}=c_{X_{2}}$ and $g_{X_{2}}=g_{X_{2}}$. The only difference between the two cases is that while internal enforcement could be positive in mixed case $X_{1}$, it is always zero in mixed case $X_{2}$, i.e., $e_{X_{1}} \geq e_{X_{2}}=0$.

Next, we compare the solutions of the centralized and mixed $X_{1}$ cases. Substituting $\left\{e_{X_{1}}, c_{X_{1}}, g_{X_{1}}\right\}$ into the FOCs of the centralized case gives

$$
\frac{\partial U_{L}}{\partial c^{i}}=-(v-z) p q^{\prime} M, \quad \frac{\partial U_{L}}{\partial g^{i}}=\left[f^{\prime \prime} m+(v-z) p+\delta g\right] \frac{(1-q) M \phi}{2\left[1-(1-q) M f^{\prime \prime}\right]}>0
$$

where $m=(1-q)(\bar{M} / 2)$ and $M=\bar{M} / 2$. To derive unambiguous results, assume as before that $v=z$. In this case, starting from the mixed $X_{1}$ case solution, the central authority should initially increase $g^{i}$ and keep $c^{i}$ unchanged. However, as $g^{i}$ changes, curve (25) shifts. Specifically, since $\partial^{2} U_{L} / \partial c^{i} \partial g^{i}>0$, as $g^{i}$ increases, the curve $\partial U_{L} / \partial c^{i}$ shifts to the right. The latter eventually shifts the curve that determines $g^{i}$ to the right as well (given by (26)), and so on. The SOC guarantees that this process stops at values of $c^{i}$ and $g^{i}$ that are higher in the centralized case relative to the mixed case.

Combining these results and given that at a symmetric equilibrium with free mobility across regions $\partial \hat{M} / \partial e^{i}=0, \partial \hat{M} / \partial c^{i}<0, \partial \hat{M} / \partial g^{i}=0$, it follows that the total number of illegal immigrants successfully entering the host country $\hat{M}$, and, consequently, the numconsider expressions (25) and (26) that determine $c$ and $g$ in the centralized case. A higher level of $c$ implies a lower $m=(\bar{M} / 2)[1-q(c)]$. A lower $m$, in turn, decreases the marginal cost of $g$ (from (26)), resulting in a higher level of $g$.

${ }^{42}$ Appendix C (attached separately) shows the details of the reasoning that explains this result. 
ber of immigrants working in each region $m$, are unambiguously lower when $c^{i}$ and $g^{i}$ are chosen by the central government.

Proposition 3. Consider a symmetric equilibrium with perfect mobility, i.e., $\tau=0$. Then, the following results hold:

1. Both $c$ and $g$ are underprovided in the completely decentralized case relative to the completely centralized case, i.e., $c_{C}>c_{D}, g_{C}>g_{D}$.

2. Suppose $v=z$. Then, the levels of $c$ and $g$ in cases $X_{1}$ and $X_{2}$ are identical, i.e., $c_{X_{1}}=c_{X_{2}}$ and $g_{X_{1}}=g_{X_{2}}$.

3. Both $c$ and $g$ in mixed case $X_{2}$ are underprovided relative to the completely centralized case, i.e., $c_{C}>c_{X_{2}}$ and $g_{C}>g_{X_{2}}$. Moreover, if $v=z$, then the latter also holds for mixed case $X_{1}$, in which case $c_{C}>c_{X_{2}}=c_{X_{1}}$ and $g_{C}>g_{X_{2}}=g_{X_{1}}$.

4. The decentralized level of internal enforcement is greater than or equal to the corresponding centralized level, i.e., $e_{D} \geq e_{C}=0$. The level of internal enforcement in case $X_{2}$ is never underprovided relative to the case $X_{1}$ and the completely centralized case. In other words, $e_{X_{2}} \geq e_{X_{1}}=e_{C}=0$.

5. The effective number of illegal immigrants in the host, and, consequently, the total number of illegal immigrants in each region, are lower in the completely centralized case relative to the completely decentralized case, i.e., $\hat{M}_{C}<\hat{M}_{D}$ and $m_{C}<m_{D}$. Similarly, $\hat{M}_{C}<\hat{M}_{X_{2}}$ and $m_{C}<m_{X_{2}}$. Moreover, if $v=z, \hat{M}_{C}<\hat{M}_{X_{2}}=\hat{M}_{X_{1}}$ and $m_{C}<m_{X_{2}}=m_{X_{1}}$.

In brief, the proposition states that under perfect mobility, the decentralization of policy decisions, which include illegal immigration enforcement and the provision of local goods, would lead to outcomes characterized by the presence of more illegal immigrants than in the centralized case. The central government limits illegal immigration by relying exclusively on border enforcement. Internal enforcement, in the model, is wasteful since it only displaces illegal immigrants from one region to the other. At the same time, since the central government is more successful at limiting the entry of illegal immigrants, it is also capable of providing higher levels of local goods to legal residents.

Our conclusions depart from those found in the traditional fiscal competition literature in an important way. In the fiscal competition, mobile factors of production are generally fixed in supply, and regional policies simply attract or displace factors from one region to the other. In our model, while internal enforcement and the provision of local goods simply encourage illegal immigrants to relocate, border enforcement can actually affect the total supply of illegal immigrants. Moreover, even though both internal and 
border enforcement are both ex-ante available as policy tools, the central government only selects the latter.

By constructing a numerical example, we can rank the solutions of all the policy variables under the alternative regimes considered above. Figures 3c, 3a, and 3b show the solution values of $c, e$, and $g$ in each case for different values of $\tau$. We focus in this section on the solutions at $\tau=0$. The exercise reveals the following ordering: $c_{C}>c_{X_{1}}=c_{X_{2}}>c_{D}$, $e_{D}>e_{X_{2}}>e_{X_{2}}=e_{C}=0$, and $g_{C}>g_{X_{1}}=g_{X_{2}}>g_{D}$. In brief, the analysis reveals that when illegal immigrants are perfectly mobile, those institutional arrangements that involve some kind of decentralized decision tend to underprovide border enforcement and the provision of local goods relative to the centralized case. It is also true that these kind of arrangements tend to rely to much on internal enforcement.

Figures $4 \mathrm{a}$ and $4 \mathrm{~b}$ show the impact of these policies on the level of illegal immigration and local wages. Notice that the largest amount of illegal immigration is observed in the decentralized case and the smallest in the centralized case. The higher level of illegal immigration in the decentralized case ends up reducing wages more relative to the centralized solution.

\subsection{Imperfect Mobility Across Regions: $\tau>0$}

The conclusions may change when illegal immigrants are imperfectly mobile once they successfully enter the host nation. We examine, in this section, the case with $\tau>0$. We mentioned earlier that the centralized solutions are independent of $\tau$. However, since the partial derivatives $\partial m^{i} / \partial e^{i}, \partial m^{i} / \partial c^{i}$, and $\partial m^{i} / \partial g^{i}$ depend on $\tau$, the decentralized solutions will change as $\tau$ changes.

Consider the completely decentralized case. Proposition 1 states that $\left|\partial^{2} m^{i} / \partial e^{i}\right|$ and $\partial m^{i} / \partial g^{i}$ decline when $\tau$ gets larger. These expressions state that as mobility costs rise the policy variables $e^{i}$ and $g^{i}$ become less effective at inducing illegal immigrants to relocate because illegal immigrants will tend to move less once they enter the host country. In the case of $e^{i}$, the latter effect combined with the fact that it is costly for the regions to enforce internal measures to detect illegal immigrants result in equilibrium levels of $e^{i}$ that tend to decline as $\tau$ rises. Eventually, $e^{i}$ may even become zero for a sufficiently large value of $\tau$. The opposite effect would be observed for $g^{i}$. With perfect mobility, 
the decentralized equilibrium is characterized by relatively low levels of $g^{i}$, mostly because regional governments do not want to attract illegal immigrants into their regions (recall that illegal immigrants consume the regionally provided good but they do not pay for it). When mobility costs rise, regions would be able to choose higher levels of $g^{i}$ given that such decisions would not attract as many illegal immigrants into the respective regions (compared to the perfect mobility case).

Proposition 1 also states that $\left|\partial m^{i} / \partial c^{i}\right|>0$ when $\tau$ increases, meaning that $c^{i}$ in fact becomes more effective in controlling illegal immigration when mobility costs rise. Taking this effect into account, it is likely to expect higher levels of $c^{i}$ as $\tau$ increases. In fact, considering that the centralized solutions do not depend on $\tau$, border enforcement in the decentralized case could even be larger than the value of $c^{i}$ centrally decided for high enough levels of $\tau$. This would happen for values of $\tau$ at which the impact of $c^{i}$ on the total pool of effective illegal immigrants more than compensates the diversionary effect that $c^{i}$ has on $m^{j}$, so that $\partial m^{j} / \partial c^{i} \leq 0$. In other words, when the mobility costs mobility costs are high enough, decentralized border enforcement may end up being higher or overprovided relative to the centralized border enforcement.

The solutions arising in each of the institutional arrangements discussed previously cannot be easily compared when $\tau>0$, at least analytically. We can gain further insights by referring to the numerical example introduced earlier. Specifically, figures (3c), (3a), and (3b) compare the solutions $\left\{c^{i}, e^{i}, g^{i}\right\}$ as a function of $\tau$ for: (i) the completely centralized case, $C$; (ii) the completely decentralized case, $D$; (iii) mixed case $X_{1}$; and (iv) mixed case $X_{2}$. The conclusions from this exercise can be summarized as follows.

First, note that $c_{X_{1}}=c_{X_{2}}$ and $g_{X_{1}}=g_{X_{2}}$ also hold for values of $\tau>0$, and not only for $\tau=0 .{ }^{43}$ Second, even though with perfect mobility $c_{D}<c_{X_{1}}<c_{C}$ and $g_{D}<g_{X_{1}}<g_{C}$, this ordering is not necessarily preserved when $\tau>0$. In particular, figures (3c) and (3b) show that border enforcement and the level of the regionally provided good increase in the decentralized case as $\tau$ increases, and when $\tau$ becomes sufficiently high, they become larger than the corresponding levels of $c$ and $g$ in the centralized and mixed cases. Note that when $\tau \rightarrow \infty$ the values of $c$ and $g$ for the fully decentralized

\footnotetext{
${ }^{43}$ This holds as long as $(v-z)=0$
} 
case and case $X_{1}$ become $\left\{c_{D}, g_{D}\right\}_{\tau \rightarrow \infty}=\{1.48,3.92\}$ and $\left\{c_{X_{1}}, g_{X_{1}}\right\}_{\tau \rightarrow \infty}=\{1.21,3.65\}$, respectively. The centralized solution does not depend on $\tau$ so that $\left\{c_{C}, g_{C}\right\}=\{1.24,3.85\}$ for all $\tau \geq 0$, which means that when it is prohibitively costly to move across regions (so immigrants must remain in the region of entry), $c$ and $g$ end up being overprovided in the decentralized case relative to the centralized case.

Third, as $\tau$ increases $e_{D}$ and $e_{X_{1}}$ decline and become zero when $\tau>1.83$ in the former case, and when $\tau>2.63$ in the latter case. Recall that $e_{C}$ and $e_{X_{2}}$ are always zero. When $\tau \rightarrow \infty$, internal enforcement becomes completely ineffective, so $e=0$ in all cases.

Finally, figures (4a) and (4b) in 4 describe the effect of the policies on the level of illegal immigration and wages in the host country for different values of $\tau$. First, note that in the mixed cases $X_{1}$ and $X_{2}$ the equilibrium values of $m^{i}$ and $w^{i}$ are identical. Second, under perfect mobility $(\tau=0)$, the lowest level of illegal immigration is achieved when the policies are centrally decided, and the highest level of $m^{i}$ in the completely decentralized case. Specifically, $m_{C}<m_{X_{1}}=m_{X_{2}}<m_{D}$. As a result $w_{C}>w_{X_{1}}=w_{X_{2}}>w_{D}$. Third, as $\tau$ rises, illegal immigration falls in the decentralized and mixed cases and it is constant in the centralized case. For high enough values of $\tau$, however, illegal immigration becomes lowest in the decentralized cases. The latter also implies that wages will be highest in the decentralized case when mobility costs are large enough.

\section{Endogenous Number of Illegal Immigrants}

We now assume that the number of potential illegal immigrants is endogenous. In this way, the illegal immigration process does not only involves deciding the region of entry and the final destination, but it also determines the total number of illegal immigrants entering the host country. Specifically, we allow for the wage in the source country to adjust depending on the number of workers in the source country. ${ }^{44}$

\footnotetext{
${ }^{44}$ The number of workers in the source country includes workers that attempted to migrate but were caught at the border. It does not include, however, workers that are caught as a result of internal enforcement. In our framework, workers that are deported as a result of internal enforcement are first compensated for their work in the host. In other words, they are deported after contributing to the production process in region $i$ of the host.
} 


\subsection{Equilibrium}

When $M^{A}$ and $M^{B}$ are endogenous, in equilibrium

$$
U_{E}^{i} \equiv q^{i}\left[w^{*}\left(\bar{n}^{*}-\hat{M}\right)-k\right]+\left(1-q^{i}\right) u_{E}^{i}-\mu^{i}\left(M^{i}\right)=w^{*}\left(\bar{n}^{*}-\hat{M}\right), \quad i=A, B .
$$

where $\hat{M}=\left(1-q^{A}\right) M^{A}+\left(1-q^{B}\right) M^{B}$. We analyze equilibria in which illegal immigrants enter through both regions. If, for instance, $U_{E}^{i}>w^{*}$, workers from the source country will only illegally enter the host through $i$. A solution with workers entering through both $i$ and $j$ necessarily entails $U_{E}^{A}=U_{E}^{B}=w^{*}$. Thus, the equilibrium when the pool of migrants is endogenously determined is defined as follows.

Equilibrium (Endogenous Supply of Immigrants). The equilibrium values $\left\{w^{A}, w^{B}\right.$, $\left.M^{A}, M^{B}, \hat{M}\right\}$ are implicitly determined by

$$
\begin{aligned}
& f^{i \prime}\left(\bar{n}^{i}+m^{i}\right)=w^{i}, \quad i=A, B, \\
& U_{E}^{i}=w^{*}\left(\bar{n}^{*}-\hat{M}\right), \quad i=A, B, \\
& \hat{M}=\left(1-q^{A}\right) M^{A}+\left(1-q^{B}\right) M^{B},
\end{aligned}
$$

where $m^{A}$ and $m^{B}$ are defined in (3) and (4), respectively. The equilibrium determines $\left\{w^{i}(x), M^{i}(x), \hat{M}(x)\right\}_{i=A, B}$, where $x=\left(c^{A}, c^{B}, e^{A}, e^{B}, g^{A}, g^{B}, \tau\right)$. By substituting the equilibrium values into (3) and (4), we obtain $m^{i}(x)$.

As before, we focus on a symmetric equilibrium of the form $M^{i}=M, m^{i}=m, w^{i}=$ $w$, where $m=\hat{M} / 2=[1-q(c)] M$. In the previous case, with a fixed supply of illegal immigrants, the (symmetric) equilibrium only depended on $c$. When the supply is endogenous, the entire policy set $\{e, g, c\}$ ultimately affects the equilibrium values. As before, we characterize the equilibrium by performing a comparative static analysis. ${ }^{45}$

A few conclusions are worth noting. First, when the supply of illegal immigrants is endogenous, changes in the policies implemented by region $i$ affect $\hat{M}$ in the following

\footnotetext{
${ }^{45}$ The results are presented in Appendix D, which is separately attached.
} 
way: ${ }^{46}$

$$
\frac{\partial \hat{M}}{\partial e^{i}}<0, \quad \frac{\partial \hat{M}}{\partial g^{i}}>0, \quad \frac{\partial \hat{M}}{\partial c^{i}}<0 .
$$

Thus, the total supply of illegal immigrants declines when internal or border enforcement increase, and the total supply increases when the provision of the local good rises.

Second, in general, the effect of the policy variables $s^{i}=\left\{e^{i}, g^{i}, c^{i}\right\}$ on $\left\{w^{A}, M^{A}, m^{A}\right.$, $\left.w^{B}, M^{B}, m^{B}\right\}$ can be decomposed in two terms. The first term is the direct effect of the policy on the equilibrium variable taking the supply of illegal immigrants as given. This term is fully described by the comparative static results studied in section 3.4. The second term includes expressions (34) and captures the indirect impact of the policy on the equilibrium variable through its effect on the supply of illegal immigrants. Consider, specifically, the effect of policy $s^{i}$ on $m^{i}$. Denote $\partial m^{i} /\left.\partial s^{i}\right|_{\text {fixed }} \hat{M}$ the effect of the policy keeping the supply of illegal immigrants constant, and $d m^{i} / d s^{i}$ the total effect, which includes the effect taking place through $\hat{M}$. Then, it follows that

$$
\frac{d m^{i}}{d s^{i}}=\left.\frac{\partial m^{i}}{\partial s^{i}}\right|_{\text {fixed } \hat{M}}+\frac{\partial m^{i}}{\partial \hat{M}} \frac{\partial \hat{M}}{\partial s^{i}} .
$$

From this last expression, we conclude that

$$
\left|d m^{i} / d e^{i}\right|>\left|\partial m^{i} / \partial e^{i}\right|, \quad d m^{i} / d g^{i}>\partial m^{i} / \partial g^{i}, \quad\left|d m^{i} / d c^{i}\right|>\left|\partial m^{i} / \partial c^{i}\right| .
$$

In other words, $m^{i}$ becomes more responsive to the policies implemented in region $i$ when the supply of illegal immigrants is endogenous. The latter holds simply because changing the policies also affects $\hat{M}$. For instance, consider an increase in $e^{i}$. The immediate effect is to reduce $m^{i}$ (and increase $m^{j}$ in the same proportion). However, a higher $e^{i}$ would also tend to reduce the supply of illegal immigrants in the host (from (34)), reducing the presence of illegal immigrants in both regions $i$ and $j$. Similar intuition holds for the policies $g^{i}$ and $c^{i}$.

\footnotetext{
${ }^{46}$ With a fixed supply of illegal immigrants, $\partial \hat{M} / \partial e^{i}=\partial \hat{M} / \partial g^{i}=0$, and $\partial \hat{M} / \partial e^{i}=-q M<0$.
} 
Third, the impact of a change in policy $s^{i}$ on the variables in region $j$ is smaller when the supply is endogenous. Consider, for example, the effect of changing $e^{i}$ on $m^{j}:^{47}$

$$
\frac{d m^{j}}{d e^{i}}=\frac{\partial m^{j}}{\partial e^{i}}+\frac{\partial m^{j}}{\partial \hat{M}} \frac{\partial \hat{M}}{\partial e^{i}}
$$

The first term is positive and captures the pure displacement effect. In fact, $\partial m^{i} / \partial e^{i}=$ $-\partial m^{j} / \partial e^{i}$. The second term, however, is negative, and partially offsets the displacement effect, making the final impact of $e^{i}$ on $m^{j}$ smaller.

Finally, from the comparative static results, it follows that $d\left(m^{i}+m^{j}\right) / d s^{i}=$ $\partial \hat{M} / \partial s^{i}$ does not depend on $\tau$ when $s^{i}=\left\{e^{i}, g^{i}\right\}$, but it depends on $\tau$ when $s^{i}=c^{i}$. This result is relevant because in the centralized case, the determination of the equilibrium policy variables depends on $\partial \hat{M} / \partial s^{i}$, which implies (as we will see later), that the centralized solution ultimately depends on $\tau$ when the supply of illegal immigrants is endogenous.

\subsection{Determination of Policy Variables}

The main implication of the previous section is that when the supply of illegal immigrants is endogenous, the policy variables do not only affect the relative attractiveness of a region (and, consequently, the localization of illegal immigrants across regions in the host country), but also affect the total pool of potential illegal immigrants. This last effect generates an externality, which typically operates in the opposite direction as the one examined in the previous section. For instance, in the case of internal enforcement, even though raising $e^{i}$ displaces illegal immigrants to region $j$, the rise in $m^{j}$ is lower since $e^{i}$ also reduces the overall amount of illegal immigrants in the host country. Taking this effect into account definitely affects how the policies are determined. We construct a series of numerical examples to examine this issue further. Figures 5 and 6 show how the equilibrium policy variables change with $\tau$ under different institutional arrangements.

From the numerical examples we conclude the following. First, the same results as in the fixed supply case hold when $\tau=0$ : cases $D$ and $X_{1}$ tend to overprovide internal enforcement relative to cases $C$ and $X_{2}$; and border enforcement and the provision of the local good is underprovided in cases $D, X_{1}$, and $X_{2}$ relative to case $C$. One important dif-

\footnotetext{
${ }^{47}$ Appendix D (attached separately) examines this issue in more detail.
} 
ference, however, is that now the equilibrium policy variables in the completely centralized case $C$ depend on $\tau$.

Second, as in the case with a fixed supply of illegal immigrants, internal enforcement is always (for all values of $\tau$ ) zero in the completely centralized and mixed $X_{2}$ cases. It decreases as $\tau$ rises in the completely decentralized and mixed $X_{1}$ cases. The main difference is that now $e_{X_{1}}$ reaches zero sooner than $e_{D}\left(e_{X_{1}}=0\right.$ for $\tau>1.7$ and $e_{D}=0$ for $\tau>2.4$ ). The reason is that when the supply of illegal immigrants is endogenous, raising $e$ generates a positive externality on both jurisdictions. This externality is partially internalized in mixed case $X_{1}$, but completely neglected in case $D$.

Third, the fact that $e_{X_{1}}=e_{X_{2}}$ for all $\tau>1.7$ has implications for the determination of the other policy variables. Specifically, the values of $c$ and $g$ are identical in these two cases when $\tau>1.7 .^{48}$

Fourth, consider the equilibrium values of $c$. We mentioned previously that $\partial \hat{M} / \partial c^{i}$ depends on $\tau$, so the centralized solution is no longer independent of $\tau$ as in the fixed supply case. Moreover, note that in all cases where border enforcement is decided centrally, $c$ falls as mobility costs rise. For the central government, $c$ becomes less "valuable" when $\tau$ is higher because less immigrants are already moving into the host. ${ }^{49}$ In the decentralized case, $c$ increases as $\tau$ rises, but $c_{D}$ is always below the corresponding values of $c_{X_{1}}, c_{X_{2}}$ and $c_{C}$.

Fifth, a similar effect takes place when considering the choice of $g$ in the completely centralized case: the value of the positive externality generated by $g$ declines as $\tau$ rises, so $g_{C}$ tends to become smaller. The opposite effect is present in the completely decentralized case, which means that $g_{D}$ increases as $\tau$ gets larger. It should be emphasized that in the decentralized case $g$ ends up being underprovided relative to the centralized case. In both mixed cases $X_{1}$ and $X_{2}, g$ increases as $\tau$ rises, with the caveat that $g_{X_{2}}>g_{X_{1}}$ for $\tau<1.7$ and $g_{X_{1}}=g_{X_{2}}$ when $\tau>1.7$.

Finally, we examine the impact of the policy choices on $\left\{m^{i}, M^{i}, w^{i}\right\}$. First, the amount of illegal immigrants attempting entry through region $i, M^{i}$, declines as mobility

\footnotetext{
${ }^{48}$ This holds, as explained earlier, because we have assumed $v=z$.

${ }^{49}$ The higher anticipated moving costs makes moving into the host less desirable, so higher levels of border enforcement would not reduce $\hat{M}$ that much.
} 
costs increase. Moreover, $M^{i}$ is always lower in the completely centralized case. Second, $m^{i}$ tends to decline in all cases, with $m^{i}$ being lowest in the centralized case. Third, wages tend to increase as $\tau$ rises in all cases, with $w^{i}$ being highest in the completely centralized case.

\section{Illegal Immigration and Income Redistribution}

So far we have assumed that legal residents in region $i$ are workers and also own the local fixed factor. We established earlier that under these conditions the net effect of illegal immigration on total income received by legal residents is positive: one additional unit of $m^{i}$ increases income in region $i$ in $\left(-f^{i \prime \prime} m^{i}\right)$. However, in this setup, illegal immigration affects wages and rents of the fixed factor in opposite directions. In this section, we analyze what happens when the ownership of factors of production is not distributed uniformly across legal residents. Specifically, ownership is divided among groups that are affected differently by the inflow of illegal immigrants.

Consider a case in which the good in region $i$ is produced using two factors of production, $n^{i}$ and $k^{i}$. Moreover, there are two types of legal residents: a group of $\bar{n}^{i}$ workers, each owning one unit of labor; and a group of $\bar{k}^{i}$ "capitalists", each owning one unit of factor $k^{i}$. The technology is represented by a constant returns to scale production function $f^{i}\left(n^{i}, k^{i}\right)$, where $n^{i}=\bar{n}^{i}+m^{i}, f_{n}^{i}>0, f_{k}^{i}>0, f_{n n}^{i}<0, f_{k k}^{i}<0$, and $f_{k n}^{i}>0$. Legal residents receive the returns from owning the respective factor of production. As before, individuals derive utility from a locally provided good and pay taxes. Suppose the utility of workers and capitalists are valued $\psi_{n}^{i}$ and $\psi_{k}^{i}$, respectively, in region $i$, with $\psi_{k}^{i}=1-\psi_{n}^{i}$. Then, total weighted utility in $i$ is defined $\operatorname{as}^{50}$

$$
U_{L}^{i}=\psi_{n}^{i} \bar{n}^{i} f_{n}^{i}+\psi_{k}^{i} \bar{k}^{i} f_{k}^{i}+\left(\psi_{n}^{i} \bar{n}^{i}+\psi_{k}^{i} \bar{k}^{i}\right)\left[\phi\left(g^{i}\right)-\frac{T^{i}}{\bar{n}^{i}+\bar{k}^{i}}\right]
$$

The FOCs in each of the cases examined earlier are similar, with the exception that expression (14) now changes to

$$
\left[\frac{-\left(\bar{n}^{i}+\bar{k}^{i}\right)}{\left(\psi_{n}^{i} \bar{n}^{i}+\psi_{k}^{i} \bar{k}^{i}\right)}\left(\psi_{n}^{i} \bar{n}^{i} f_{n n}^{i}+\psi_{k}^{i} \bar{k}^{i} f_{k n}^{i}\right)+\left(v^{i}-z^{i}\right) p^{i}+\delta^{i} g^{i}\right]
$$

\footnotetext{
${ }^{50}$ This utility specification would arise, for instance, in a context where individuals belong to different interest groups and policies are determined by the outcome of a probabilistic voting model.
} 
Since the production exhibits CRS, it follows that $-f_{n n}^{i} m^{i}=\bar{n}^{i} f_{n n}^{i}+\bar{k}^{i} f_{k n}^{i}$. Hence if $\psi_{n}^{i}=\psi_{k}^{i}=1 / 2$, then the conclusions from the previous sections are unchanged. However, as the weight attached to labor increases, i.e., as $\psi_{n}^{i}$ rises and $\psi_{k}^{i}$ falls, expression $\left(\psi_{n}^{i} \bar{n}^{i} f_{n n}^{i}+\right.$ $\left.\psi_{k}^{i} \bar{k}^{i} f_{k n}^{i}\right)$ tend to increase, meaning that the costs for region $i$ of one additional unit of $m^{i}$ gets larger. Note that the cost is highest when $\psi_{n}^{i}=1, \psi_{k}^{i}=0$, and it is lowest, and, in fact, negative, when $\psi_{n}^{i}=0, \psi_{k}^{i}=1$.

So how does this redistributive consideration affect the equilibrium policy choices? We construct a numerical example to address this issue. The numerical example evaluates how the equilibrium levels of $\left\{e^{i}, c^{i}, g^{i}\right\}$ change with $\psi_{n}^{i}$ in the completely centralized and decentralized cases, assuming $\tau=0 .{ }^{51}$ Figures 7 and 8 present the results of such exercise.

A few remarks are worth noticing. First, figure 7 a shows that $e_{C}$ is always zero (from Proposition 2), but higher levels of $\psi_{n}$ are associated with higher levels of internal enforcement in the decentralized, i.e., $e_{D}{ }^{\prime}\left(\psi_{n}\right)>0$. Even though changing internal enforcement does not end up affecting the number of illegal immigrants in the region, ${ }^{52}$ the decentralized decision of $e_{D}$ leads regional governments to choose higher levels of $e_{D}$ when the weight attached to labor is larger. This happens, partly, because the costs of one additional immigrant are higher when $\psi_{n}$ is relatively large, as stated above.

Second, figures $7 \mathrm{~b}$ and $7 \mathrm{c}$ show that the level of the regional good and border enforcement increase in both the completely centralized and decentralized cases as $\psi_{n}$ rises. ${ }^{53}$ The intuition works as follows. For a pro-labor government the presence of a higher number of illegal immigrants is relatively more costly, so they will choose a higher level of border enforcement. A higher level of $c$, in turn, reduces the effective number of illegal immigrants in $i,{ }^{54}$ which also decreases the marginal cost of rasing $g$. It results from equation (26) that $g$ ends up being higher. ${ }^{55}$

\footnotetext{
${ }^{51}$ We still consider a symmetric equilibrium, which assumes, among other things, $\psi_{n}^{A}=\psi_{n}^{B}$, and the weights are the same for both the regional and national levels. Also, we examine only these two extreme cases because similar conclusions hold for mixed $X_{1}$ and $X_{2}$ cases).

${ }^{52}$ At least when the total pool of potential illegal immigrants is fixed.

${ }^{53}$ Since $\tau=0$, then it follows from Proposition 3 that $c_{C}\left(\psi_{n}\right)>c_{D}\left(\psi_{n}\right)$ and $c_{C}\left(\psi_{n}\right)>c_{D}\left(\psi_{n}\right)$ for all $\psi_{n}$. Similar conclusions hold for values of $\tau>0$, with the caveat that for large enough values of $\tau, e_{D}\left(\psi_{n}\right)=0$ for all $0 \leq \psi_{n} \leq 1$, and the curves $c_{D}\left(\psi_{n}\right)$ and $g_{D}\left(\psi_{n}\right)$ are above the curves $c_{C}\left(\psi_{n}\right)$ and $g_{C}\left(\psi_{n}\right)$, respectively.

${ }^{54}$ Recall that at a symmetric equilibrium, $m=[1-q(c)] M$.

${ }^{55}$ We also showed earlier that $\partial^{2} U_{L} / \partial c^{i} \partial g^{i}>0$, so that a higher level of $c$ would result in a higher level of $g$ as well.
} 
And, third, figures 8 show that the implementation of these policies end up affecting the number of illegal immigrants in $i$ and the wages. Specifically, as $\psi_{n}$ rises, $m^{i}$ declines and $w^{i}$ rises, as expected.

\section{Conclusions and Extensions}

Many states in the USA have recently passed laws granting state governments the authority to enforce illegal immigration policies. This paper investigates the economic impact of such initiatives using a model of border and internal enforcement of illegal immigration within a spatial framework. Specifically, the paper examines the determinants of internal and border enforcement policies and the levels of regionally provided goods under four institutional arrangements: (i) completely centralized case; (ii) completely decentralized case; (iii) regional governments choose internal enforcement and the level of regional goods and the federal government chooses the level of border enforcement; and (iv) regional governments decide the level of the regional goods and the federal government chooses both border and internal enforcement.

The analysis shows that the outcome of implementing illegal immigration policies varies significantly depending on which level of government is involved in the decision process. The most salient conclusions can be summarized as follows. First, the level of internal enforcement (in a symmetric equilibrium) is always zero in the completely centralized case. In other words, a central government would only rely on border enforcement to control illegal immigration. Second, in the decentralized cases the solutions depend on the cost for illegal immigrants of moving across regions once they have successfully entered the host country. If illegal immigrants are perfectly mobile across regions, then internal enforcement tends to be overprovided and border enforcement and the regional good underprovided in the decentralized cases. As a result, the level of illegal immigration is higher and domestic wages end up being lower in these cases. Third, as mobility costs rise, internal enforcement efforts tend to decline while border enforcement tends to increase in the decentralized cases. Under complete immobility, internal enforcement becomes completely irrelevant in all cases. Moreover, the levels of both border enforcement and the regional good could even be higher when decisions are completely decentralized compared to the fully centralized outcome. Fourth, when the number of (potential) illegal immigrants is endogenous, then 
all policy variables affect the supply of effective illegal immigrants in the host nation, generating an additional external effect. This externality generally works in a countervailing direction of the diversionary effect that characterizes the exogenous case.

The basic setup of the model developed in the paper can be extended in several different ways. For instance, one can consider a richer spatial configuration that includes both bordering and non-bordering (interior) states. It may also be useful to consider the non-discernment case (when firms do not know for sure whether they are hiring an illegal immigrant or not). This setup might be more suitable to describe the emergence of information sharing arrangements between regional and federal governments, such as Everify. The consideration of workers with different skill levels, facing different mobility costs is another avenue for further research. Finally, international mobility of complementary factors like capital will add a relevant dimension to this research program. 


\section{References}

Amuedo-Dorantes, Catalina and Cynthia Bansak (2012). "The labor market impact of mandated employment verification systems". In: The American Economic Review 102.3, pp. $543-548$.

Amuedo-Dorantes, Catalina, Thitima Puttitanun, and AnaP. Martinez-Donate (2013). "How Do Tougher Immigration Measures Affect Unauthorized Immigrants?" English. In: Demography 50.3, pp. 1067-1091.

Bandyopadhyay, Subhayu and Sudeshna Champati Bandyopadhyay (1998). "Illegal immigration: A supply side analysis". In: Journal of Development Economics 57.2, pp. 343360.

Bohn, Sarah, Magnus Lofstrom, and Steven Raphael (2014). "Did the 2007 Legal Arizona Workers Act reduce the state's unauthorized immigrant population?" In: Review of Economics and Statistics 96.2, pp. 258-269.

Bond, Eric W. and Tain-Jy Chen (1987). "The welfare effects of illegal immigration". In: Journal of International Economics 23.3, pp. 315-328.

Brown, Charles C and Wallace E Oates (1987). "Assistance to the Poor in a Federal System". In: Journal of Public Economics 32.3, pp. 307-330.

Brueckner, Jan K. (2000). "Welfare reform and the race to the bottom: Theory and evidence". In: Southern Economic Journal, pp. 505-525.

Brueckner, Jan K (2004). "Fiscal decentralization with distortionary taxation: Tiebout vs. tax competition". In: International Tax and Public Finance 11.2, pp. 133-153.

Djajić, Slobodan (1987). "Illegal aliens, unemployment and immigration policy". In: Journal of Development Economics 25.1, pp. 235-249.

Djajić, Slobodan and Michael S. Michael (2014). "Controlling Illegal Immigration: On the Scope for Cooperation with a Transit Country". In: Review of International Economics 22.4 , pp. 808-824.

Ethier, Wilfred J. (1986). "Illegal immigration: The host-country problem". In: The American economic review, pp. 56-71.

Gaytan-Fregoso, Helena and Sajal Lahiri (2000). "Foreign aid and illegal immigration". In: Journal of Development Economics 63.2, pp. 515-527. 
Gordon, Roger H. and Julie B. Cullen (2012). "Income redistribution in a federal system of governments". In: Journal of Public Economics 96.11, pp. 1100-1109.

Hanson, Gordon H. (2006). "Illegal Migration from Mexico to the United States". In: Journal of Economic Literature 44.4, pp. 869-924.

Oates, Wallace E. and Robert M. Schwab (1988). "Economic competition among jurisdictions: efficiency enhancing or distortion inducing?" In: Journal of public economics 35.3 , pp. 333-354.

Orrenius, Pia and Madeline Zavodny (2014). How do e-verify mandates affect unauthorized immigrant workers? Working Papers 1403. Federal Reserve Bank of Dallas.

Orrenius, Pia M. and Madeline Zavodny (2005). "Self-selection among undocumented immigrants from Mexico". In: Journal of Development Economics 78.1, pp. 215-240.

Pauly, Mark V (1973). "Income redistribution as a local public good". In: Journal of Public economics 2.1, pp. 35-58.

Pena, Anita Alves (2014). "Undocumented Immigrants and the Welfare State: The Case of Regional Migration and US Agricultural Labor". In: Journal of Regional Science 54.1, pp. $96-113$.

Spilimbergo, Antonio and Gordon H. Hanson (1999). "Illegal Immigration, Border Enforcement, and Relative Wages: Evidence from Apprehensions at". In: American economic review 89.5, pp. 1337-1357.

Wildasin, David E. (1986). Urban public finance. Harwood Academic Publishers.

Wilson, John D. (1986). "A theory of interregional tax competition". In: Journal of urban Economics 19.3, pp. 296-315.

Woodland, Alan D. and Chisato Yoshida (2006). "Risk preference, immigration policy and illegal immigration". In: Journal of Development Economics 81.2, pp. 500-513. 


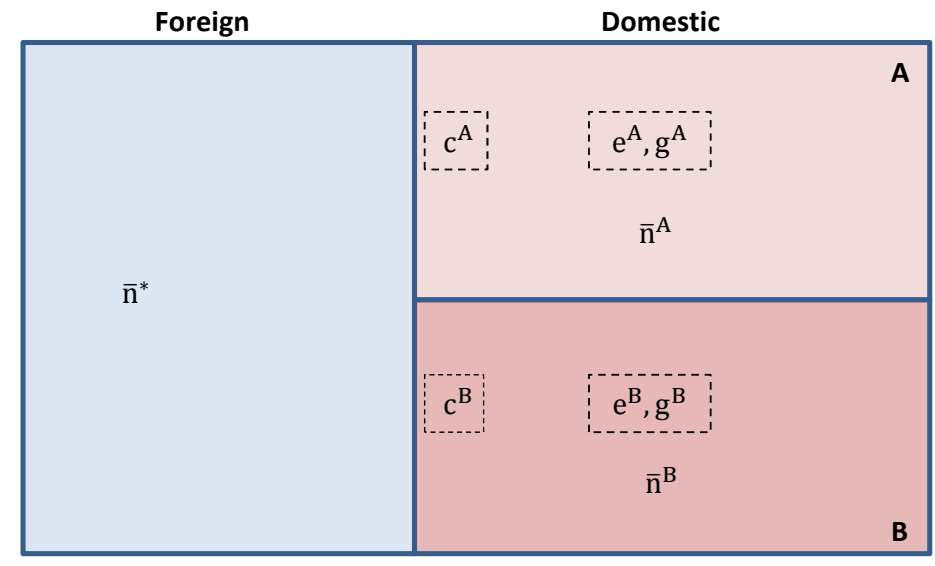

(a)

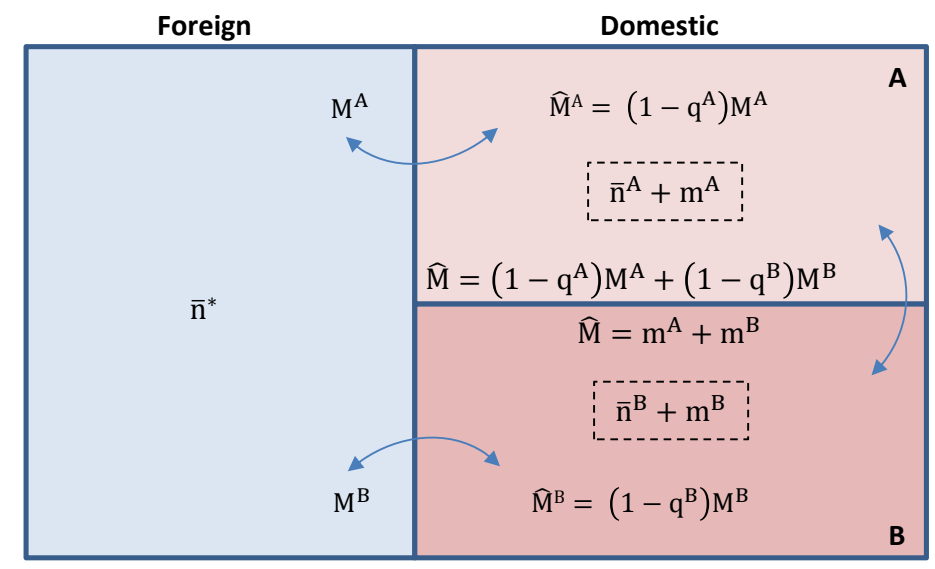

(b)

Figure 1: Model description 


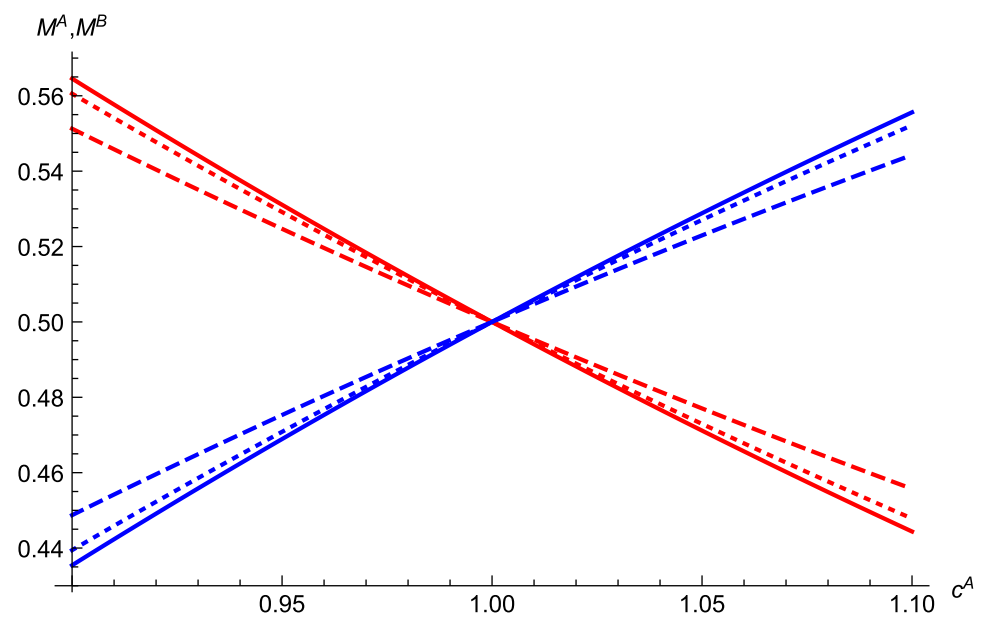

$-M^{A}(\tau=0)$

. - $M^{A}(\tau=0.5)$

- - $M^{A}(\tau \rightarrow \infty)$

$-M^{B}(\tau=0)$

-. $M^{B}(\tau=0.5)$

- $M^{B}(\tau \rightarrow \infty)$

(a) $M^{i}$

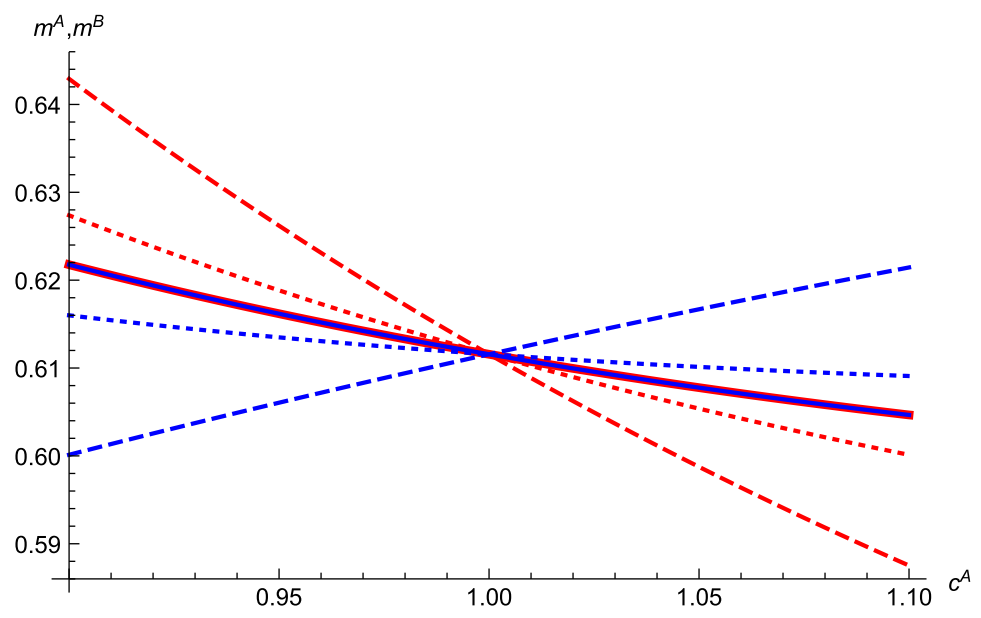

$m^{A}(\tau=0)$

- - $m^{A}(\tau=0.5)$

- $m^{A}(\tau \rightarrow \infty)$

- $m^{B}(\tau=0)$

$\cdots m^{B}(\tau=0.5)$

- $m^{B}(\tau \rightarrow \infty)$

(b) $m^{i}$

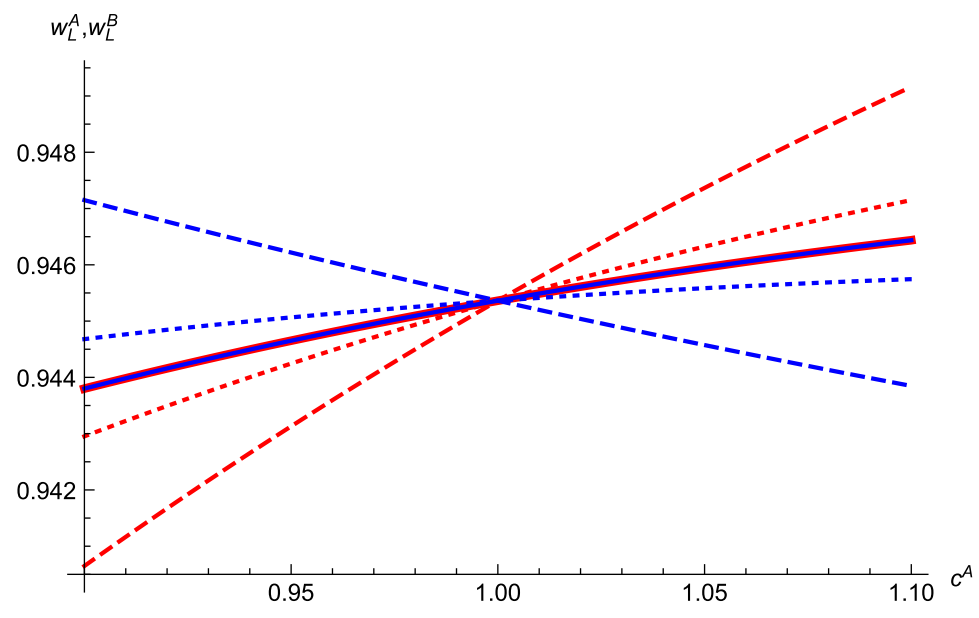

$w_{L}^{A}(\tau=0)$

- - $w_{L}^{A}(\tau=0.5)$

- - $w_{L}^{A}(\tau \rightarrow \infty)$

$-w_{L}^{B}(\tau=0)$

-. $w_{L}^{B}(\tau=0.5)$

- - $w_{L}^{B}(\tau \rightarrow \infty)$

(c) $w^{i}$

Figure 2: Comparative statics with respect to $c^{i}$ 


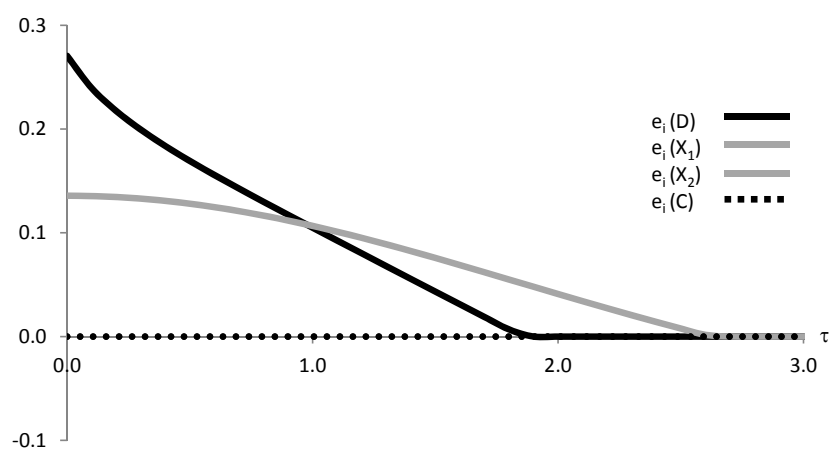

(a) $e^{i}$

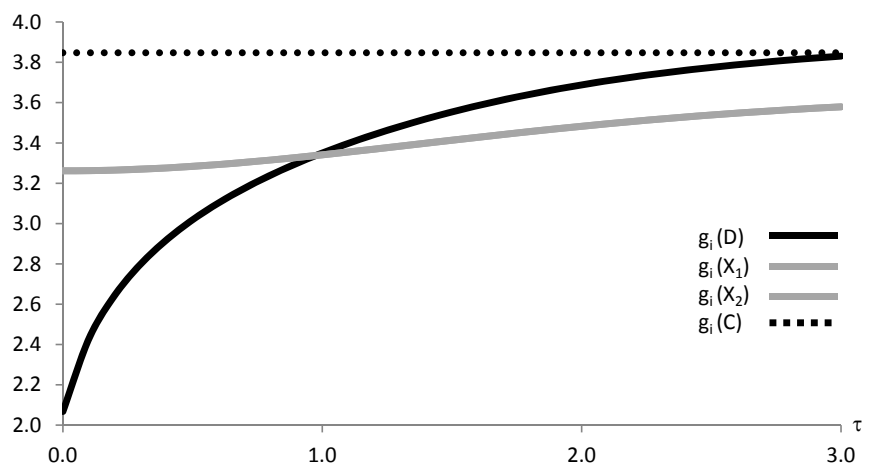

(b) $g^{i}$

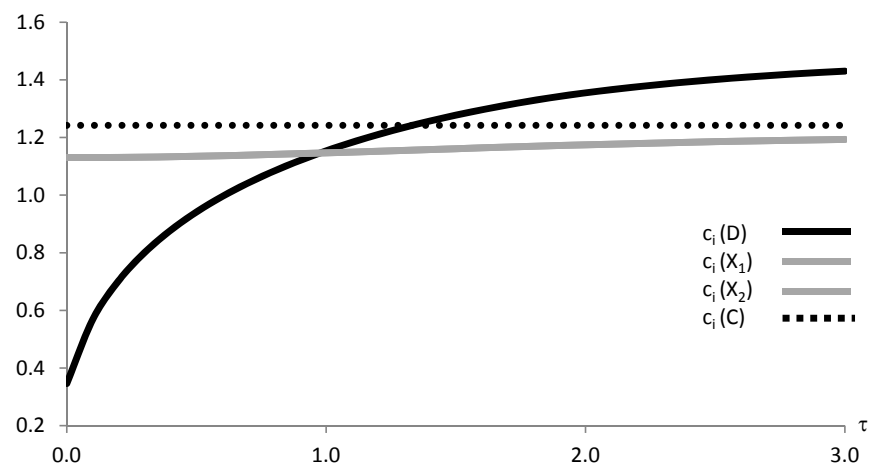

(c) $c^{i}$

Figure 3: Fixed supply of illegal immigrants: $\left\{e^{i}, g^{i}, c^{i}\right\}$ as a function of $\tau$ 


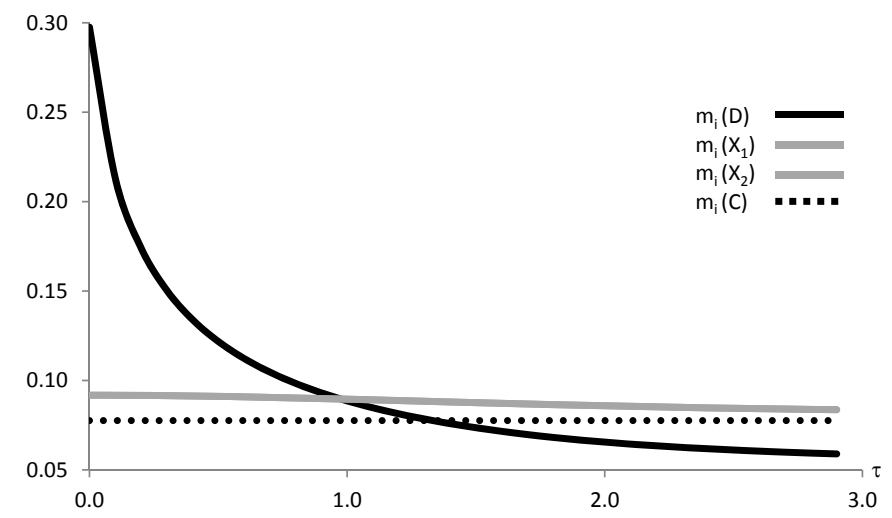

(a) $m^{i}$

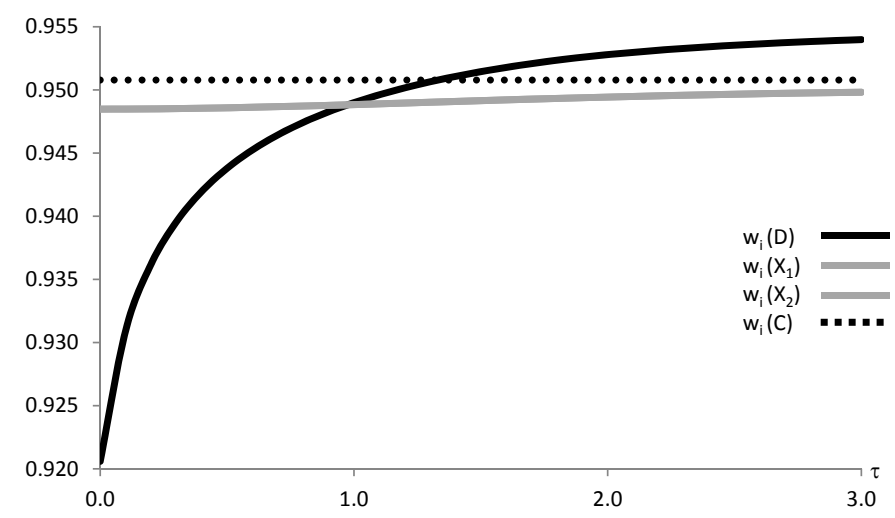

(b) $w^{i}$

Figure 4: Fixed supply of illegal immigrants: $\left\{m^{i}, w^{i}\right\}$ as a function of $\tau$ 


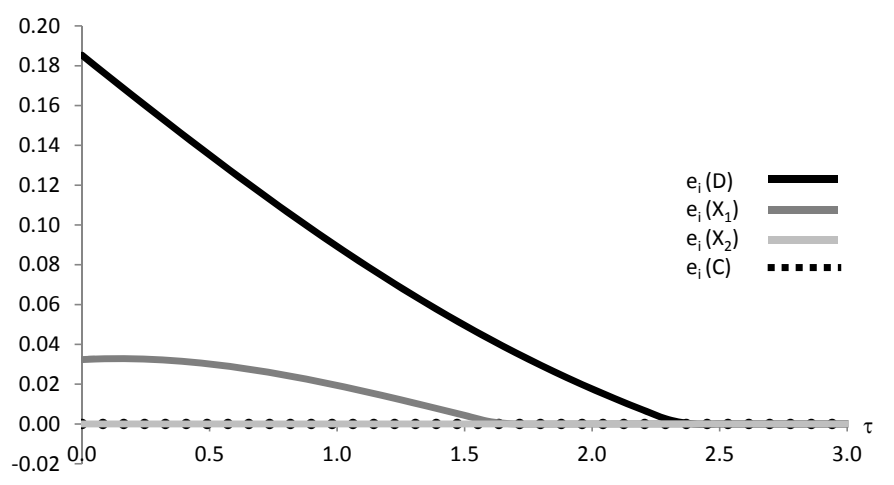

(a) $e^{i}$

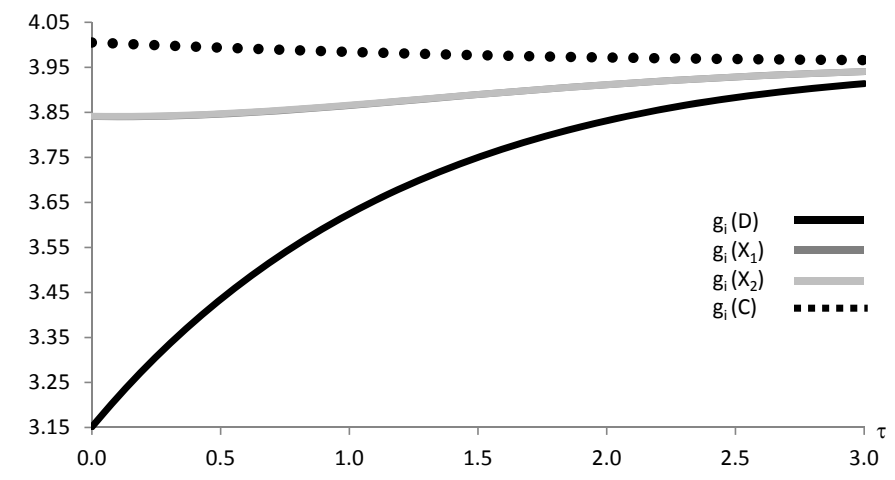

(b) $g^{i}$

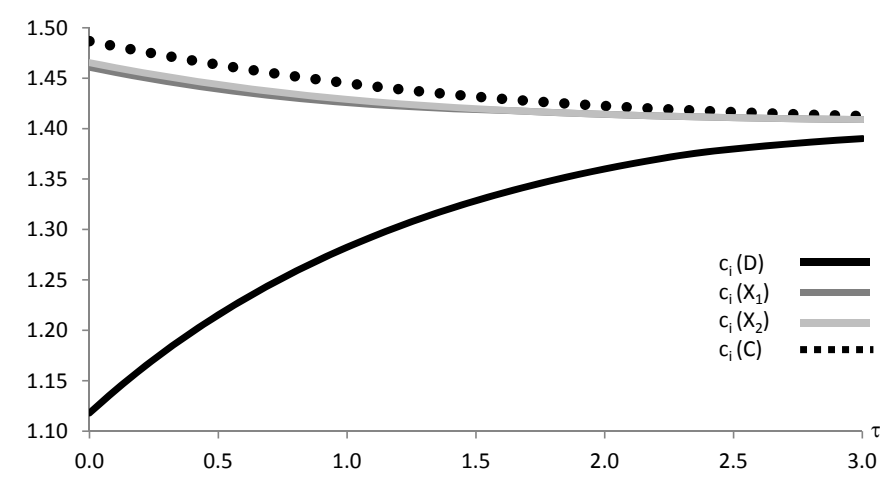

(c) $c^{i}$

Figure 5: Endogenous supply of illegal immigrants: $\left\{e^{i}, g^{i}, c^{i}\right\}$ as a function of $\tau$ 


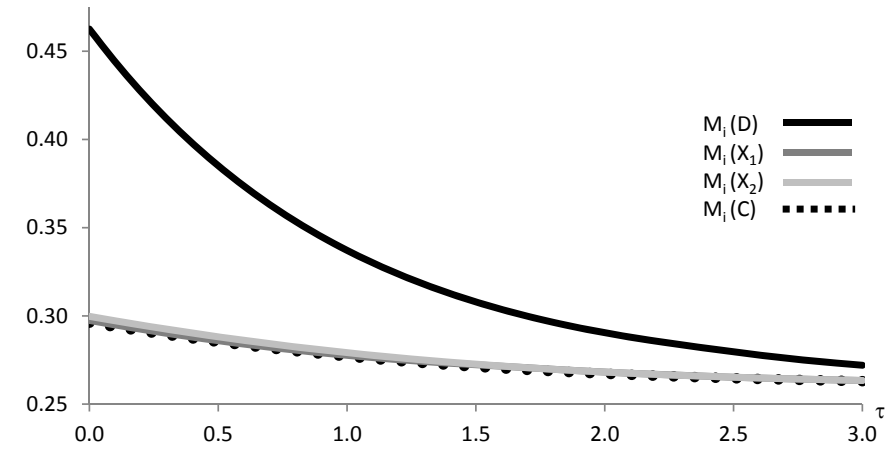

(a) $M^{i}$

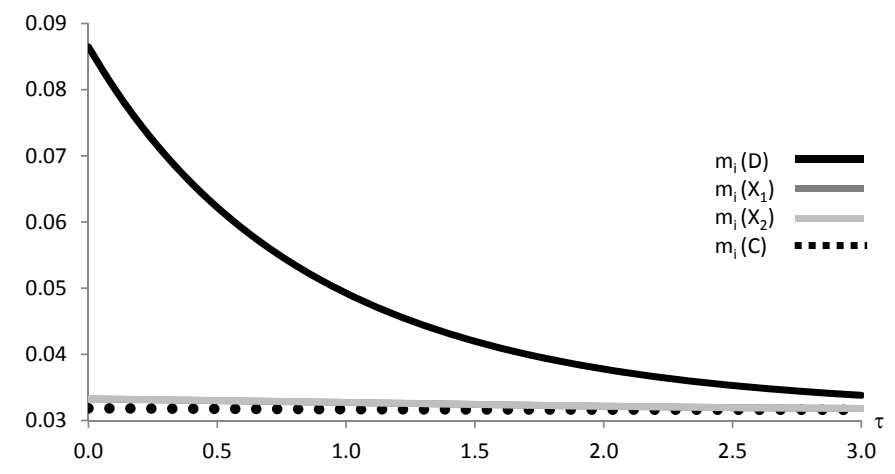

(b) $m^{i}$

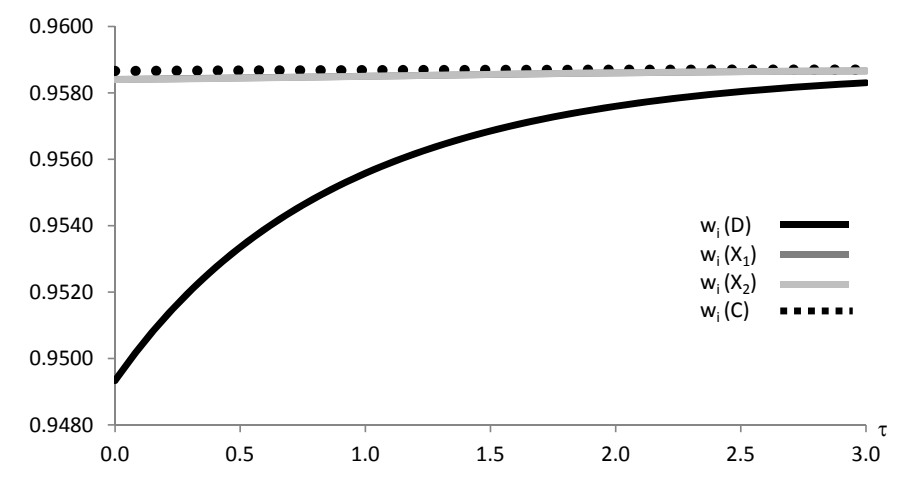

(c) $w^{i}$

Figure 6: Endogenous supply of illegal immigrants: $\left\{M^{i}, m^{i}, w^{i}\right\}$ as a function of $\tau$ 


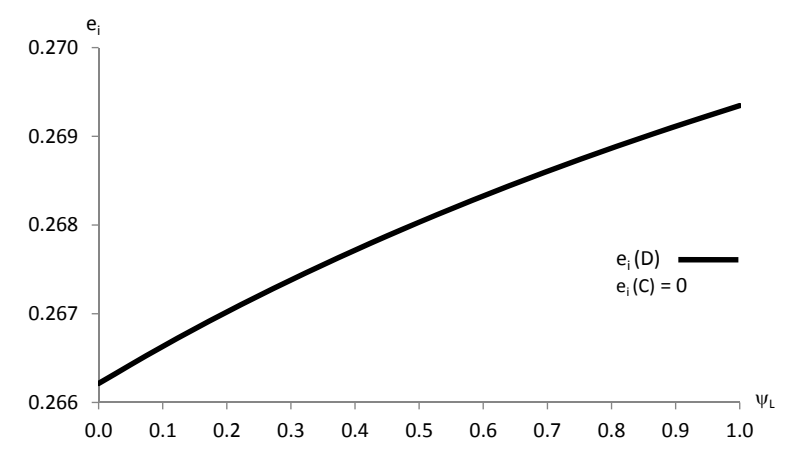

(a) $e^{i}$

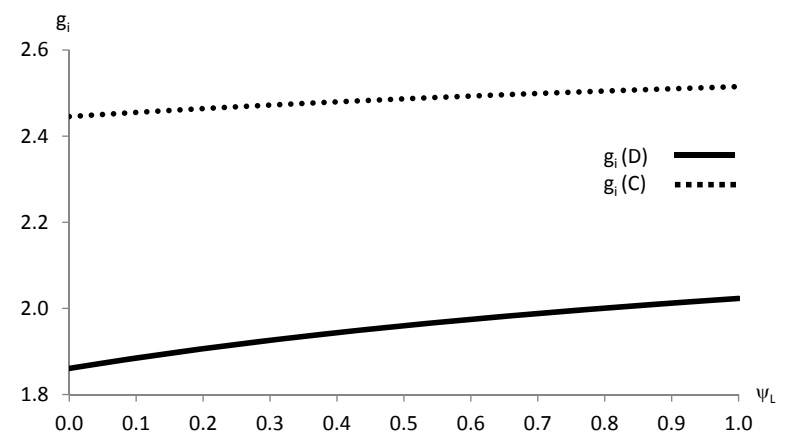

(b) $g^{i}$

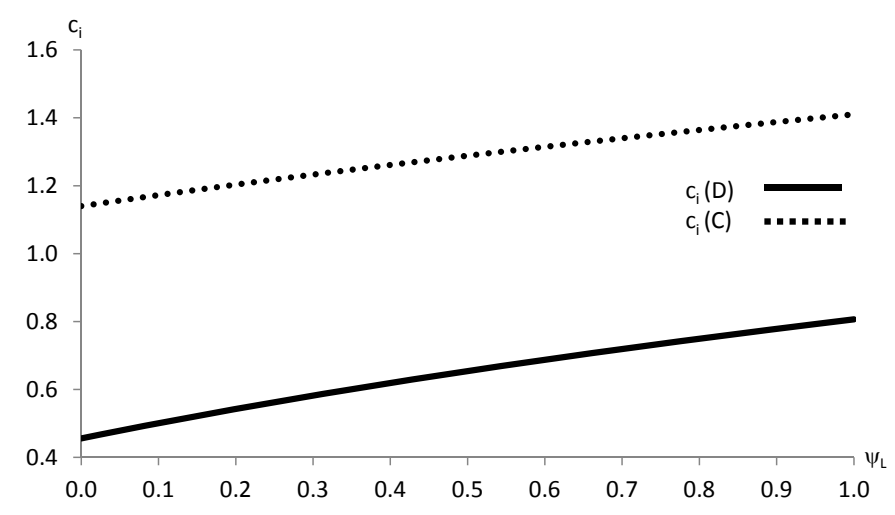

(c) $c^{i}$

Figure 7: Illegal immigration and income redistribution: $\left\{e^{i}, g^{i}, c^{i}\right\}$ as a function of $\psi_{L}$ 


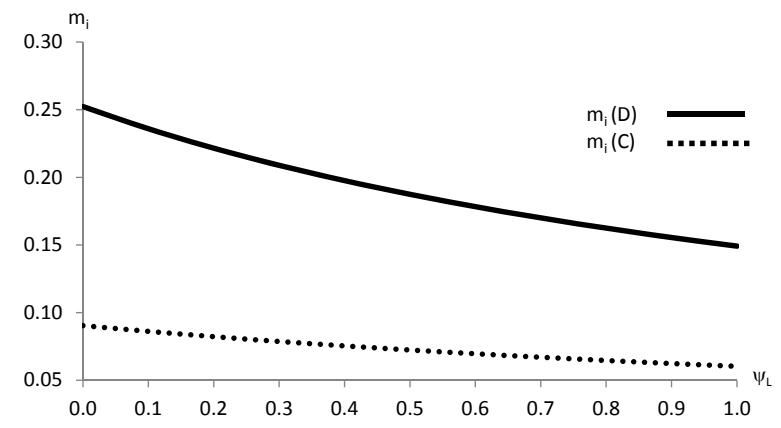

(a) $m^{i}$

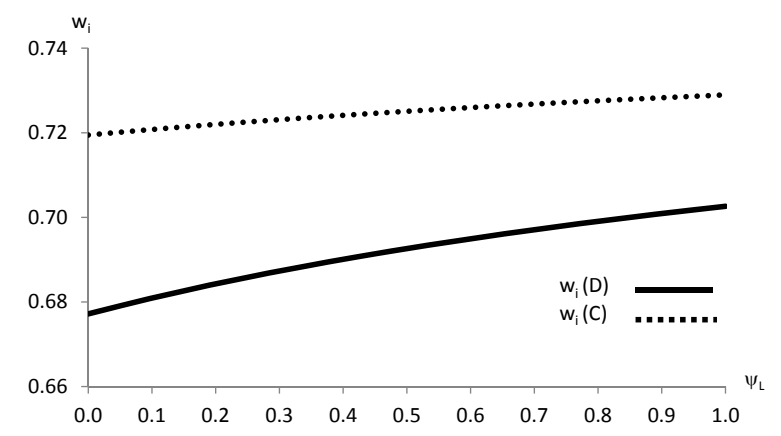

(b) $w^{i}$

Figure 8: Illegal immigration and income redistribution: $\left\{m^{i}, w^{i}\right\}$ as a function of $\psi_{L}$ 